\title{
Analysis of Temperature Extremes over India Using Sheffield \& IMD Dataset
}

\section{Anurag Sharma}

Indian Institute of Technology Mandi

Deepak Swami ( $\nabla$ drdswami@hotmail.com )

IIT Mandi: Indian Institute of Technology Mandi https://orcid.org/0000-0003-4904-2810

Nitin Joshi

Indian Institute of Technology Jammu

\section{Research Article}

Keywords: Extreme temperature indices, India, IMD, Sheffield, Modified Mann-Kendall Test

Posted Date: August 17th, 2021

DOI: https://doi.org/10.21203/rs.3.rs-662326/v1

License: (c) (1) This work is licensed under a Creative Commons Attribution 4.0 International License. Read Full License 


\title{
Analysis of Temperature Extremes over India Using Sheffield \& IMD Dataset
}

Anurag Sharma ${ }^{1}$, Deepak Swami ${ }^{2}$, Nitin Joshi ${ }^{3}$

1 Research Scholar School of Engineering, Indian Institute of Technology Mandi, Mandi, Himachal Pradesh175005, Email:-anuragsharma.nith@gmail.com

2 Assistant Professor, School of Engineering, Indian Institute of Technology Mandi, Mandi, Himachal Pradesh175005, Email:-deepak@iitmandi.ac.in

3 Assistant Professor, Department of Civil Engineering, Indian Institute of Technology Jammu, J\&K-181221, Email:-nitin.joshi@iitjammu.ac.in

Corresponding author: Deepak Swami (deepak@iitmandi.ac.in)

Present address: Assistant Professor, School of Engineering, Indian Institute of Technology Mandi, Mandi, Himachal Pradesh-175005

\begin{abstract}
Temperature extremes significantly contribute to climate change; therefore, the analysis of temperature extremes is essential in detecting and attributing climate change. The present study aims to analyze the spatiotemporal variations in the temperature extremes over India, using $0.25^{\circ} \times 0.25^{\circ}$ high-resolution Sheffield temperature gridded dataset for a period of 62 years (1951-2012). In addition, the spatial distribution, statistical relation and trend pattern of Sheffield's temperature dataset is compared with $1^{\circ} \times 1^{\circ}$, gridded temperature dataset of Indian Meteorological Department (IMD). The mean of temperature indices show nearly similar spatial distribution in both datasets; however trend pattern of extreme indices show significant differences over different homogeneous temperature regions of India. There is mostly disagreement between the two datasets, for trend patterns of extreme indices at different homogeneous regions, but few grids show reasonable agreement for similar trend pattern. Both datasets reported a significant decreasing trend in TX10p (amount of cool days) and TN10p (amount of cold nights) at maximum grids for the 1951-2012 period. In addition, a significant increasing trend in TX90p (amount of hot days) and WSDI (warm spell duration indicator) at maximum grids during post-1981 and 1951-2012 is observed in both datasets. A comprehensive insight into different characteristics (spatial distribution, statistical relation and trend patterns) of Sheffield's temperature dataset will help in understanding the applicability of Sheffield temperature dataset for climate modeling and prediction studies over India.
\end{abstract}

Keywords: Extreme temperature indices; India; IMD; Sheffield; Modified Mann-Kendall Test 


\section{Introduction}

Climate change is a complex phenomenon that significantly affects different sectors like agriculture, ecosystem, water supply, energy production, human society, etc. (Mall et al. 2006a, b; Ravindranath et al. 2006; Zhu and Troy 2018; Vinnarasi and Dhanya 2019). Frequent extreme events such as drought, floods, heatwave, etc. have been attributed to climate change (Aggarwal and Singh 2010). Many extreme climate events result either from natural climate variability or through anthropogenic changes in the climate. The occurrence of extreme climate events could result in economic losses that are often expressed as a proportion of gross domestic product (GDP). In developing countries, the agriculture sector is most vulnerable to the extreme climate events and significantly impacts the GDP. Temperature is one of the key parameters of climate that significantly contributes to climate fluctuations (Karl et al. 1993). The analysis of temperature is helpful in detection and attribution of climate change. As per Intergovernmental Panel on Climate Change (IPCC) (IPCC 2007, 2014) warming in climate system is observed due to unprecedented changes in surface and atmospheric temperature from 1950 onwards. It is also observed that the magnitude of the temperature extreme is increasing at a higher rate than the average temperature (Sterl et al. 2008). Therefore, the analysis of temperature extremes from 1950 onwards is important for understanding the warming climate system. Numerous studies are conducted which analyze the changes in temperature extremes at global (Frich et al. 2002; Zhang et al. 2005; Alexander et al. 2006; Mall et al. 2006b; Andrade et al. 2012; Mishra et al. 2015) as well as at regional scale (Dash and Mamgain 2011; Zhou and Ren 2011; Panda et al. 2014; Tao et al. 2014; Vinnarasi et al. 2017; Sharma et al. 2018; Sharma and Goyal 2020). In the Asia-Pacific region, during 1961-2003 period a significant increasing trend in maximum (Tmax) and minimum (Tmin) temperature is reported at 64\% and 79\% stations respectively (Griffiths et al. 2005). The annual mean maximum and minimum temperature extremes are found to increase by $0.17{ }^{\circ} \mathrm{C} /$ decade and $0.24{ }^{\circ} \mathrm{C} /$ decade respectively since the mid-1950s (Choi et al. 2009). The significant increase in the annual number of hot days and warm nights and significant decreases in the annual number of cool days and cold nights were observed during the 1961 to 1998 period over Southeast Asia and the South Pacific (Manton et al. 2001). A significant decrease in the annual occurrence of cold nights and a significant increase in the annual occurrence of warm nights was observed over 70\% of the global land area for the period 1951-2003 (Alexander et al. 2006). The statistically significant increases in the percentage of warm nights/days and decreases in the percentage of cold nights/days were observed at 70\% of the stations in central and south Asia for the period 1961-2000 (Klein Tank et al. 2006).

Long-term annual and seasonal trend analysis of surface air temperature over pan India has indicated significant warming trends in mean, maximum, and minimum temperature value (Dash and Hunt 2007; Kothawale et al. 2010). Dash et al., 2007 studied the characteristics of changes in maximum and minimum temperature over seven homogeneous temperature regions in India. They report that the maximum temperature has been increasing over all the regions during last century, while the minimum temperature was decreasing in northern regions during the period 1955-1972 and after this period it started increasing. Vinnarasi et al., 2017 reported $0.36{ }^{\circ} \mathrm{C}$ increase in mean Diurnal Temperature Range (DTR) during 1951-1980 and decrease in rate after 1980 over different climatic zones in India. The significant increase in frequency, persistency and spatial coverage of cold wave (CW) and severe cold wave (SCW) is observed in different parts of India (Punjab, Rajasthan and Jammu \& Kashmir) during 1971-2000 (Pai et al. 2004). Several studies report an increase in the frequency, intensity and duration of heatwaves over India (Ratnam et al. 2016; Mishra et al. 2017; Mukherjee and Mishra 2018; Nanditha et al. 2020). Different regions (north, northwest, central and northeast Peninsula) across India have experienced heatwave (HW) days of $\geq 8$ HW days on an average per hot weather season (March- July) (Pai et al. 2013). The spatial extent of heatwaves is also found significantly increasing in northwest India, peninsular India, northeast India and significantly decreasing in hilly regions and central northeast India during period 1951-2010 (Sharma and Mujumdar 2017). It is evident from past studies that robust signal of warming is present in the temperature extremes (Dash and Mamgain 2011; Panda et al. 2014). Therefore, analysis of temperature extremes over different time windows is needed to get insightful picture of changing climate scenario. The accurate temperature dataset is key component for studying and analyzing the changing climate system, climate models and different hydrological processes. The primary source to accurate temperature dataset is quality-controlled weather stations. The data obtained from these whether stations are point measurements however, spatially distributed dataset are required for more systematic and detailed analysis (Abatzoglou 2013; Behnke et al. 2016). The spatially distributed dataset includes those fine scale variations which arises due to topographical features. So the highresolution gridded temperature dataset is preferred for evaluating regional climate models and hydrological 
processes (Caldwell et al. 2009; Walton et al. 2015). Many global or continental-scale reanalysis datasets are available (e.g., Sheffield, NARR, MERRA, NOAA-20CR and ERA-20C). The "reanalysis dataset" is often downscaled to higher resolution either using bilinear interpolation or using dynamical downscaling (Stefanova et al. 2012); (Cosgrove et al. 2003; Kanamaru and Kanamitsu 2007; Stefanova et al. 2012; Xia et al. 2012; Walton et al. 2015). The present study is based on the hypothesis that the "station based dataset" and "reanalysis dataset" can have significant differences in their characteristics and trend patterns for same region under consideration. Therefore, it is important to compare these datasets before using them for hydrological and climate change studies.

Numerous studies on temperature extremes, have pointed out robust signal of warming over different homogeneous regions in India, however these studies are carried out using a coarse-resolution girded dataset $\left(1^{\circ} \times 1^{\circ}\right)$. The diverse topography and large spatial variation in the climatic condition over India demands to analyze change in temperature extremes at a finer resolution. Therefore, the present study aims to analyze the spatiotemporal variations and trends in the temperature extremes over India, at finer resolution of $0.25^{\circ} \times 0.25^{\circ}$. For this analysis, the Sheffield temperature gridded dataset for a period of 62 years (1951-2012) is used. In addition, the spatial distribution, statistical relation and trend pattern of Sheffield's temperature dataset is compared with $1^{\circ} \times 1^{\circ}$, gridded temperature dataset of Indian Meteorological Department (IMD). The extreme temperature indices analyzed in this study are defined by 'Expert Team on Climate Change Detection and Indices' (ETCCDI) (Alexander and Herold 2016).

\section{Data and methods}

\subsection{Study area and data}

The Indian Institute of Tropical Meteorology (IITM), Pune, has divided the whole India into seven homogeneous temperature regions on basis of spatial and temporal variations in surface air temperatures. These regions are the east coast (EC), interior peninsula (IP), north central (NC), northeast (NE), northwest (NW), western Himalaya (WH), and west coast (WC) (see Figure 1). Two different gridded datasets are used in this study; the first dataset is $0.25^{\circ} \times 0.25^{\circ}$, Sheffield's gridded daily maximum and minimum temperature data which is a blend of observational and reanalyses datasets (Sheffield et al. 2006). This dataset is used for the 1951-2012 period with spatial resolution covering Indian landmass. The Sheffield datasets have been widely used in different regional level studies on climate and hydrological modeling (Sheffield and Wood 2007; Troy et al. 2011; Wang et al. 2011; Sheffield et al. 2012; Demaria et al. 2013).

The second dataset is $1^{\circ} \times 1^{\circ}$, daily maximum and daily minimum temperature data from Indian Meteorological Department (IMD) (Panda et al. 2014). The daily temperature data from 395 observation stations were interpolated to gridded data using a modified version of Shephard's angular distance weighing algorithm (Shepard 1968). This gridded dataset has a spatial domain from $7.5^{\circ} \mathrm{N}-37.5^{\circ} \mathrm{N}$ and $67.5^{\circ} \mathrm{E}-97.5^{\circ} \mathrm{E}$, and it is also used for the period 1951-2012. Few grids in western Himalaya, northeast, and the Andaman and Nicobar Islands are not analyzed for the IMD dataset. Mishra et al., (2014) compared the daily maximum and minimum temperature dataset from Sheffield et al., (2006) and IMD for the overlapping period (1969-2005). They observed that the daily temperatures from Sheffield et al., (2006) captured the seasonal cycle along with temporal and spatial variability reasonably well in India. The analysis in this study is performed in respective grids without any re-gridding.

Fig. 1 Location map for the study area showing homogeneous temperature regions in India.

\subsection{Extreme Temperature Indices}

The extreme temperature indices computed and analyzed in this study are defined by the Expert Team on Climate Change Detection and Indices (ETCCDI). Only nine extreme temperature indices which are relevant with the climatology of India are analysed. The indices are calculated on an annual basis from 1951 to 2012 (62 years periods) with base period 1961-1990. The statistical analysis on these indices is performed in three different time windows 1951-1981 (pre-1981), 1982-2012 (post-1981) and 1951-2012. The indices used in this study are given in Table 1. 
Table 1 Extreme Temperature Indices (Here TX = Daily Max Temp., TN = Daily Min Temp.)

\subsection{Modified Mann-Kendall (MK) trend test}

The modified Mann-Kendall (MK) trend test proposed by Yue and Wang, (2004) is used to estimate extreme temperature indices trends. The significance of the trend is examined at 5\% significance level. The Mann-Kendall (MK) test has been widely used to detect the trend in various hydro-climatic variables (Jain and Kumar 2012; Anghileri et al. 2014; Suryavanshi et al. 2014; Joshi et al. 2016). The limitation with the MK test is that the time series data should be free from serial correlation, since the presence of serial correlation in the data leads to false rejection of null hypothesis (type-I error) (Hamed and Ramachandra Rao 1998). The serial correlation in the data affects the MK test variance while the modified MK test incorporates a modified value of variance. The significance of trend is assessed using R package 'modifiedmk' (Patakamuri and O'Brien 2019).

The modified variance $V^{*}(S)$ is given by

$V^{*}(S)=V(S) \cdot \frac{n}{n^{*}}$

Where $n$ is the actual sample size (ASS) of actual sample data, $n^{*}$ is the effective sample size

(ESS), and $\frac{n}{n^{*}}$ is termed as correction factor.

The ESS is given by (Bayley and Hammersley 1946):

$n^{*}=\frac{n}{1+2 \cdot \sum_{k=1}^{n-1}\left(1-\frac{k}{n}\right) \cdot \rho_{k}}$

Where $\rho_{k}$ is the lag-k serial correlation coefficient, which can be represented by the sample lag-k serial correlation coefficient, given by (Salas et al.,1980):

$r_{k}=\frac{\left.\frac{1}{n-k} \sum_{t=1}^{n-k}\left(X_{t}-\bar{X}_{t}\right)\left(X_{t+k}-\bar{X}_{t}\right)\right)}{\frac{1}{n} \sum_{t=1}^{n}\left(X_{t}-\bar{X}_{t}\right)^{2}}$

$\bar{X}_{t}=\frac{1}{n} \sum_{t=1}^{n} X_{t}$

Here $r_{k}$ is called the lag-k serial correlation coefficient, $k$ represents the time lag (or distance) between the correlated pairs $\left(X_{t}, X_{t+k}\right)$ and $\bar{X}_{t}$ is the sample mean.

\section{Results and Discussion}

\subsection{Spatial variability in Tmax and Tmin}

Prior to analyzing trends in extreme temperature indices, it is important to analyse the spatial mean and distribution of Tmax (daily maximum temperature) and Tmin (daily minimum temperature) of both Sheffield and IMD. The spatial distribution of mean Tmax (daily maximum temperature) for the period 1951-2012 shows significant spatial variability over WH, NE; and in few grids at NC, NW for both the datasets (Fig. 2a, 2c). The spatial distribution of mean Tmax for both the datasets is nearly similar at NC, IP, WC, EC, and in maximum grids at NW. The difference in the spatial distribution for both datasets is observed at WH, NE, and few grids at NC, NW. The maximum and minimum value of mean Tmax at WH, NE, NC, and NW in IMD data is significantly different from the maximum and minimum value in Sheffield data. Like the spatial distribution of mean Tmax, the mean Tmin (daily minimum temperature) for the period 1951-2012 shows similar spatial variability at WH, NE, and few grids at NC, NW for both the datasets (see Fig. 2b, 2d). The spatial distribution of mean Tmin for both the datasets is observed nearly similar at NC, IP, WC, EC, and in maximum grids at NW. The maximum and minimum value of mean Tmin at WH, NE, NC, and NW in IMD data is significantly different compared to the maximum and minimum value in Sheffield data. The pooled mean Tmax comparison for both datasets using box-plot and probability density function plot is shown in Fig. 2e and Fig. 2g, respectively. A similar comparison of pooled mean Tmin for both datasets is shown in Fig. $2 \mathrm{f}$ and Fig. $2 \mathrm{~h}$. The grids with inconsistent data with the IMD dataset are excluded in calculating pooled mean Tmax and Tmin for the Sheffield dataset. Using the two-sample Wilcoxon 
rank-sum test, significant ( $\mathrm{p}$-value $\leq 0.05$ ) difference in the mean of pooled mean Tmax of IMD and Sheffield; and non-significant ( $\mathrm{p}$-value $>0.05$ ) difference in the mean of pooled mean Tmin of IMD and Sheffield is observed. The two-sided Kolmogorov-Smirnov test confirms that the distribution of pooled mean Tmax and Tmin in IMD is significantly ( $\mathrm{p}$-value $\leq 0.05$ ) different compared to the distribution of pooled mean Tmax and Tmin in Sheffield.

Fig 1 Mean Tmax for period 1951-2012 (a) IMD (c) Sheffield; Mean Tmin for period 1951-2012 (b) IMD (d) Sheffield; Grids with inconsistent data are shown in grey color. Box plot for pooled mean Tmax (e) and mean Tmin (g). Probability density function for pooled mean Tmax (g) and mean Tmin (h); Blue and red color curves represent IMD and Sheffield dataset, respectively. Statistical significance was estimated using the Ranksum and KS tests for mean and distributions of pooled mean data.

\subsection{Spatial variability and trends in DTR}

The spatial distribution of mean DTR for 1951-2012 shows large spatial variability over pan India for both the datasets analyzed (see Fig. 3a, 3b). Although the spatial distribution is nearly similar at every homogeneous temperature region for both the datasets, a slight difference is observed in few grids located at the NW and NC region boundary. The maximum and minimum value of mean DTR at different homogeneous regions in IMD data is nearly same as the maximum and minimum value in Sheffield data (see Fig. 3a, 3b). For the IMD data, the mean DTR value for the pre-1981, post-1981, and 1951-2012 period is 11.83, 11.95, and 11.89, respectively. Whereas, for the Sheffield data, the mean DTR value for the pre-1981, post-1981, and 1951-2012 period is 11.64 , 11.43, and 11.54, respectively (see Fig. 3e, 3f). The spatial variance of DTR for IMD and Sheffield datasets are shown in Fig 3c and 3d, respectively. For the IMD dataset, the spatial variance of DTR shows a decreasing trend during the pre-1981 and post-1981 period, and the trend during the pre-1981 period is statistically significant. For the Sheffield dataset, a non-significant increasing trend in spatial variance is observed during the pre-1981 and post-1981 period. For both the datasets, the spatial variance during the pre-1981 period is higher compared to the post-1981 period. The high peak values of spatial variance is observed in the Sheffield dataset compared to the IMD dataset.

Fig 2 Mean DTR for period 1951-2012 (a) IMD (b) Sheffield ; DTR spatial variance over India, asterisk denotes significant trend (at 5\% significance level) (c) IMD (d) Sheffield ; DTR Box Plot for three time windows (e) IMD (f) Sheffield ; DTR trend (at 5\% significance level) in three time windows for IMD (g)19511981 (h)1982-2012 (i)1951-2012, for Sheffield (j)1951-1981 (k)1982-2012 (1)1951-2012; Grids with significant increasing trend, significant decreasing trend, no trend and inconsistent data are shown in red, blue, white and grey color respectively; Pie chart on right side shows percentage of grids having significant increasing, significant decreasing and no trend.

The trend pattern of DTR observed in IMD data is distinct from the trend pattern observed in Sheffield data. IMD dataset shows grid-wise spatially coherent significant increasing trend at NW, NC, IP, WC, EC, NE (pre-1981) and at IP, WC, EC (post-1981 and 1951-2012). However, in the Sheffield dataset, the grid-wise spatially coherent significant increasing trend is observed in most of the grids at WH (pre-1981), at NW, NC, IP, EC (post-1981), and at IP, WC, EC (1951-2012). The significant decreasing trend with good spatial coherence is observed in IMD data at NW, NC, and NE (post-1981), while in Sheffield data spatially coherent significant decreasing trend is observed at WH (post-1981 and 1951-2912) and at NW, NC, NE (1951-2012). With IMD data, compared to the pre-1981 and 1951-2012 period, the percentage of grids showing a significant increasing (decreasing) trend is less (more) in the post-1981 period; however, the contradictory result is observed with Sheffield data. Contrasting trend results are also observed with IMD and Sheffield datasets in all three-time windows. IMD dataset is showing a significant increasing trend in maximum grids at NE (pre-1981 and 1951-2012) and in few grids at NC (19512012); however, the Sheffield dataset is showing a significant decreasing trend. Similarly, the IMD dataset shows 
a significant decreasing trend in few grids at NW (post-1981), while the Sheffield dataset shows a significant increasing trend.

DTR shows significant increasing trend at 68\% (pre-1981), 30\% (post-1981) and 52\% (1951-2012) grids in IMD data. These results are found consistent with the trend pattern observed in past studies (Panda et al. 2014; Vinnarasi et al. 2017). The significant increasing trend of DTR in Sheffield data is observed at 12\% (pre-1981), $43 \%$ (post1981), and $11 \%$ (1951-2012) grids. Overall, there is mostly disagreement between the two datasets for significant increasing and significant decreasing trend patterns during pre-1981 and 1951-2012. A better agreement between the two datasets can be noted, with a significant increasing trend in few grids at IP, WC, and EC (post-1981 and 1951-2012).

\subsection{Spatial variability and trends in TX10p}

The spatial distribution of mean TX10p for the period 1951-2012 shows significant spatial variability over pan India for both the datasets analyzed (see Fig. 4a, 4b). The spatial distribution of both the datasets is nearly similar at $\mathrm{WH}$ and consistently varying at other homogeneous temperature regions. The maximum and minimum values of TX10p at different homogeneous regions are different for IMD and Sheffield data (see Fig. 4a, 4b). For the IMD data, the mean TX10p value for the pre-1981, post-1981, and 1951-2012 periods is $11.38,8.90$, and 10.14, respectively. However, for Sheffield data, the mean TX10p value for the pre-1981, post-1981, and 1951-2012 period is 10.78, 7.87, and 9.33, respectively (see Fig. 4e, 4f). A lower value of mean TX10p is obtained from Sheffield data for all the time windows. For both the dataset, the spatial variance of TX10p show a decreasing trend in the pre-1981 and post-1981-time periods. However, a significant decreasing trend of spatial variance with IMD and Sheffield data is found during the pre-1981 and post-1981 period, respectively (see Fig. 4c, 4d). In IMD data, the spatial variance is higher for the post-1981 period than in the pre-1981 period, while in Sheffield, both pre-1981 and post-1981 periods show nearly similar higher spatial variance. The higher peak values of spatial variance is observed in the IMD dataset compared to the Sheffield dataset.

Fig 3 Mean TX10p for period 1951-2012 (a) IMD (b) Sheffield ; TX10p spatial variance over India, asterisk denotes significant trend at 5\% significance level) (c) IMD (d) Sheffield ; TX10p Box Plot for three time windows (e) IMD (f) Sheffield; TX10p trend (at 5\% significance level) in three time windows for IMD (g)1951-1981 (h)1982-2012 (i)1951-2012, for Sheffield (j)1951-1981 (k)1982-2012 (l)1951-2012; Grids with significant increasing trend, significant decreasing trend, no trend and inconsistent data are shown in red, blue, white and grey color respectively; Pie chart on right side shows percentage of grids having significant increasing, significant decreasing and no trend.

The trend pattern of TX10p observed in IMD data is nearly similar to the trend pattern observed in Sheffield data. In IMD data, the significant increasing trend with good spatial coherence is observed in few grids at WH, NW, NC, NE (pre-1981); and at NW, NC, NW (post-1981 and 1951-2012). A spatially coherent significant increasing trend in the Sheffield dataset is observed in maximum grids at WH, NW, NC, and NE (pre-1981). The significant decreasing trend with good spatial coherence in IMD data is observed at NW, WC, IP, EC, and NE in all threetime windows, although grids showing a significant decreasing trend are spatially inconsistent. In Sheffield data, except for few grid points at IP, WC, EC, NW (post-1981); and at WH, NW, NC, NE (1951-2012), rest of the grids show a spatially coherent significant decreasing trend. In both IMD and Sheffield data, compared to the pre1981 and 1951-2012 period, the percentage of grids showing a significant increasing (decreasing) trend is less (more) in the post-1981 period. Contrasting trend results are also observed with IMD and Sheffield datasets in all three-time windows. The IMD dataset shows a significant increasing trend in few grids at NC and NE (post-1981), whereas the Sheffield dataset shows a significant decreasing trend. The IMD dataset shows a significant decreasing trend in few grids at NE (pre-1981), whereas; Sheffield dataset shows a significant increasing trend.

TX10p shows significant decreasing trend at 42\% (pre-1981), 56\% (post-1981) and 67\% (1951-2012) grids in IMD data. Earlier studies have also confirmed the significant decrease in the percentage of cool days across different regions in India (Klein Tank et al. 2006; Vinnarasi et al. 2017). The significant decreasing trend of 
TX10p in Sheffield data is observed at 87\% (post-1981) and 82\% (1951-2012) grids. The good agreement between the two datasets, for both significant increasing and significant decreasing trend patterns, can be noted during the pre-1981 and 1951-2012 period.

\subsection{Spatial variability and trends in TN10p}

The spatial distribution of mean TN10p for the period 1951-2012 shows significant variability in few grids at NC, IP with IMD data, and less variability with Sheffield data (see Fig. 5a, 5b). The difference in the spatial distribution of both datasets is observed in few grids at NC, IP, and NE. The maximum and minimum value of mean TN10p at different homogeneous regions in IMD data is different compared to the maximum and minimum value in Sheffield data. For the IMD data, the mean value of TN10p for the pre-1981, post-1981, and 1951-2012 periods is $9.44,7.90$, and 8.67 , respectively. Sheffield data also exhibit similar mean values $10.84,7.01$, and 8.92 , for the pre-1981, post-1981, and 1951-2012 period, respectively (see Fig. 5e, 5f). For the IMD dataset, the spatial variance of TN10p shows an increasing trend during pre-1981 and a significant decreasing trend during post-1981 (see Fig 5c, 5d). The spatial variance in Sheffield data shows a decreasing trend in both pre-1981 and post-1981 periods, and both trends are statistically significant. In IMD data, the spatial variance is higher for the post-1981 period, whereas in Sheffield pre-1981 period shows a higher spatial variance. The high peak values of spatial variance is observed in the IMD dataset compared to the Sheffield dataset.

Fig 4 Mean TN10p for period 1951-2012 (a) IMD (b) Sheffield ; TN10p spatial variance over India, asterisk denotes significant trend (at 5\% significance level) (c) IMD (d) Sheffield; TN10p Box Plot for three time windows (e) IMD (f) Sheffield; TN10p trend (at 5\% significance level) in three time windows for IMD (g)1951-1981 (h)1982-2012 (i)1951-2012, for Sheffield (j)1951-1981 (k)1982-2012 (1)1951-2012; Grids with significant increasing trend, significant decreasing trend, no trend and inconsistent data are shown in red, blue, white and grey color respectively; Pie chart on right side shows percentage of grids having significant increasing, significant decreasing and no trend.

The trend pattern of TN10p observed in IMD data is nearly similar to the trend pattern observed in Sheffield data. Both IMD and Sheffield data show a significant increasing trend with good spatial coherence in most of the grids at WH, NW, NC, and NE (pre-1981); however, the spatial coherence is more in IMD data as compared to Sheffield data. The significant decreasing trend in IMD data is observed in most of the grids at WH, NW, NC, and NE (post1981 and 1952-2012). In Sheffield data, a significant decreasing trend with good spatial coherence is observed in all homogeneous temperature regions (post-1981 and 1951-2012) except in few grids at NW, NC and WC. In both IMD and Sheffield data, compared to the pre-1981 and 1951-2012 period, the percentage of grids showing a significant increasing (decreasing) trend is less (more) in the post-1981 period. In some cases contrasting trend results are observed with IMD and Sheffield datasets. The IMD dataset shows a significant increasing trend in few grids at IP (post-1981 and 1951-2012); however, the Sheffield dataset shows a significant decreasing trend.

TN10p shows a predominant significant decreasing trend at 81\% (post-1981) and 52\% (1951-2012) grids in IMD data. A significant decrease in the percentage of cool nights in India is also reported in past studies (Panda et al. 2014; Vinnarasi et al. 2017). A similar dominant significant decreasing trend is observed at $88 \%$ (post-1981) and 92\% (1951-2012) grids in Sheffield data. The good agreement between the two datasets, for both significant increasing and significant decreasing trend patterns, can be noted during the pre-1981 and post-1981 period.

\subsection{Spatial variability and trends in TX90p}

The spatial distribution of mean TX90p for the period 1951-2012 shows less spatial variability over pan India for both the datasets analyzed (see Fig. 6a, 6b). Though the spatial distribution is almost similar for both datasets, a slight difference is observed in few grids at NW and WC. The maximum and minimum value of mean TX90p at NW and WC in IMD data is significantly different compared to the maximum and minimum value in the Sheffield data. In IMD data, the mean TX90p value for the pre-1981, post-1981, and 1951-2012 period is 9.63, 13.40, and 11.51, respectively. However, in Sheffield data, the mean TX90p value for pre-1981, post-1981, and 1951-2012 period is 10.05 , 13.03, and 11.54, respectively (see Fig. 6e, 6f). For the IMD dataset, the grid-based spatial variance shows an increasing trend for both periods; however, the trend in the post-1981 period is found statistically significant. The spatial variance in Sheffield is decreasing during the pre-1981 period and increasing 
during the post-1981 period; however, the increasing trend during post-1981 is found statistically significant. For both the datasets, the spatial variance during the post-1981 period is higher than the pre-1981 period (see Fig 6c, $6 \mathrm{~d}$ ). The high peak values of spatial variance is observed in the IMD dataset compared to the Sheffield dataset.

Fig 5 Mean TX90p for period 1951-2012 (a) IMD (b) Sheffield ; TX90p spatial variance over India, asterisk denotes significant trend (at 5\% significance level) (c) IMD (d) Sheffield ; TX90p Box Plot for three time windows (e) IMD (f) Sheffield; TX90p trend (at 5\% significance level) in three time windows for IMD (g)1951-1981 (h)1982-2012 (i)1951-2012, for Sheffield (j)1951-1981 (k)1982-2012 (l)1951-2012; Grids with significant increasing trend, significant decreasing trend, no trend and inconsistent data are shown in red, blue, white and grey color respectively; Pie chart on right side shows percentage of grids having significant increasing, significant decreasing and no trend.

The trend pattern of TX90p observed in IMD data is nearly similar to the trend observed in Sheffield data. In IMD data, except at WH (pre-1981), the significant increasing trend with good spatial coherence is observed at all homogeneous regions in all three-time windows. However, in Sheffield data, the significant increasing trend with high spatial coherence is observed at all homogeneous temperature region during post-1981 and 1951-2012. The significant decreasing trend in IMD data is also observed at few grids, i.e., WH, WC, NE (pre-1981); at IP (post1981); and NW, NC (1951-2012). In Sheffield data, the few grids at WH, NE (post-1981); and at NE, NC, IP, WC, NE (1951-2012) show a significant decreasing trend. In both IMD and Sheffield data, compared to the pre1981 and 1951-2012 period, the percentage of grids showing a significant increasing (decreasing) trend is less (more) in the post-1981 period. Contrasting trend results are observed with IMD and Sheffield datasets. The IMD dataset shows a significant increasing trend in few grids at NC, NW, IP, and WC (pre-1981); however, the Sheffield dataset shows a significant decreasing trend. The spatially coherent significant increasing trend is observed at WH (pre-1981) with Sheffield data; however, no trend is observed with IMD data.

TX90p shows predominant significant increasing trend at 65\% (pre-1981), 83\% (post-1981) and 82\% (19512012) grids in IMD data. The earlier regional (Panda et al. 2014; Vinnarasi et al. 2017), as well as global studies (Klein Tank et al. 2006) have also observed a significant increase in the number of hot days. The predominant significant increasing trend in Sheffield data is observed at $86 \%$ (post-1981) and 71\% (1951-2012) grids. The good agreement between the two datasets for significant increasing trend patterns can be noted during the post1981 and 1982-2012 period.

\subsection{Spatial variability and trends in TN90p}

The spatial distribution of mean TN90p for the period 1951-2012 shows significant spatial variability over pan India for both the datasets analyzed. The difference in the spatial distribution of both the dataset is observed in few grids at NC, NE and IP (see Fig. 7a, 7b). The maximum and minimum value of mean TN90p at different homogeneous regions in IMD data is different compared to the maximum and minimum value in Sheffield data. In IMD data, the mean TN90p value for the pre-1981, post-1981, and 1951-2012 period is 12.05, 13.71, and 12.88, respectively. However, in Sheffield data, the mean TN90p value for pre-1981, post-1981, and 1951-2012 period is $9.79,15.27$, and 12.53 , respectively (see Fig. $7 \mathrm{e}, 7 \mathrm{f}$ ). The grid-based spatial variance of TN90p shows a significant decreasing trend for the pre-1981 period and a significant increasing trend for the post-1981 period in both the datasets. The spatial variance is higher for both pre-1981 and post-1981 periods in IMD data, whereas, in Sheffield, only the pre-1981 period shows higher spatial variance (see Fig 7c, 7d). The high peak values of spatial variance is observed in the IMD dataset compared to the Sheffield dataset.

Fig 6 Mean TN90p for period 1951-2012 (a) IMD (b) Sheffield ; TN90p spatial variance over India, asterisk denotes significant trend (at 5\% significance level) (c) IMD (d) Sheffield; TN90p Box Plot for three time windows (e) IMD (f) Sheffield ; TN90p trend (at 5\% significance level) in three time windows for IMD (g)1951-1981 (h)1982-2012 (i)1951-2012, for Sheffield (j)1951-1981 (k)1982-2012 (l)1951-2012; Grids with significant increasing trend, significant decreasing trend, no trend and inconsistent data are shown in red, blue, white and grey color respectively; Pie chart on right side shows percentage of grids having significant increasing, significant decreasing and no trend 
The trend pattern of TN90p observed in IMD data is nearly similar to the trend pattern observed in Sheffield data. In IMD data, the significant increasing trend with good spatial coherence is observed at NW, NC, and NE (post1981). The significant increasing trend observed in few grids in IMD data at IP (post-1981 and 1951-2012); and at NW, NC, and EC (1952-2012) is spatially less coherent. In Sheffield data, the significant increasing trend with high spatial coherence is observed in maximum grids at every homogeneous temperature region during the post1981 and 1951-2012 period. The spatially coherent significant decreasing trend in IMD data is observed at WH, NW, NC, and NE (pre-1981); however, in Sheffield data, a spatially coherent significant decreasing trend is observed at WH, NW, NC (pre-1981). The significant decreasing trend in IMD data is also observed in few scattered grids at IP (post-1981 and 1951-2012). In IMD data, compared to the pre-1981 and 1951-2012 period, the percentage of grids showing a significant increasing (decreasing) trend is less (more) in the post-1981 period. However, in Sheffield data, the percentage of grids showing significant increasing (decreasing) trends is less (more) in the 1951-2012 period compared to the pre-1981 and post-1981 period. IMD dataset shows a significant decreasing trend in few grids at IP and NE (pre-1981); however, the Sheffield dataset shows a significant increasing trend. The spatially coherent significant increasing trend is observed at WH and NE (1951-2012) with Sheffield data; however, no trend is observed with IMD data.

TN90p shows significant increasing trend at 12\% (pre-1981), 67\% (post-1981) and 34\% (1951-2012) grids in IMD data. Earlier studies have also reported a significant increase in the percentage of warm nights at the global (Manton et al. 2001) and the regional level (Panda et al. 2014). The dominant significant increasing trend in Sheffield data is observed at 75\% (post-1981) and 92\% (1951-2012) grids. The good agreement between the two datasets, for significant increasing and significant decreasing trend patterns, can be noted during the post-1981 and pre-1981 periods, respectively.

\subsection{Spatial variability and trends in TR}

The spatial distribution of mean TR for the period 1951-2012 shows large spatial variability over pan India for both the datasets analyzed. The major difference in spatial distribution is observed in few grids at NC and NE (see Fig. 8a, 8b). The maximum and minimum value of mean TR at NC and NE in IMD data is significantly different compared to the maximum and minimum value in Sheffield data. The mean value of TR for IMD data during the pre-1981, post-1981, and 1951-2012 periods is 199.11, 200.28, and 199.69, respectively. However, in Sheffield data, the mean TR value for the pre-1981, post-1981, and 1951-2012 period is 182.11, 188.73, and 185.42, respectively (see Fig. 8e, 8f). The Sheffield data shows a lower value of mean TR at all the three-time windows. For IMD data, the spatial variance of TR shows a significant increasing trend during pre-1981 and a significant decreasing trend during the post-1981 period. The spatial variance in Sheffield data shows an increasing trend in both pre-1981 and post-1981 periods; however, only increasing trend in the pre-1981 period is found statistically significant. The spatial variance is higher for the pre-1981 period in both the datasets (see Fig 8c, 8d). The high peak values of spatial variance is observed in the Sheffield dataset compared to the IMD dataset.

Fig 7 Mean TR for period 1951-2012 (a) IMD (b) Sheffield ; TR spatial variance over India, asterisk denotes significant trend (at 5\% significance level) (c) IMD (d) Sheffield ; TR Box Plot for three time windows (e) IMD

(f) Sheffield ; TR trend (at 5\% significance level) in three time windows for IMD (g)1951-1981 (h)1982-2012

(i)1951-2012, for Sheffield (j)1951-1981 (k)1982-2012 (1)1951-2012; Grids with significant increasing trend, significant decreasing trend, no trend and inconsistent data are shown in red, blue, white and grey color respectively; Pie chart on right side shows percentage of grids having significant increasing, significant decreasing and no trend.

The trend pattern of TR observed in IMD data is nearly similar to the trend pattern observed in Sheffield data. With IMD data, a significant increasing trend with good spatial coherence is observed in grids at WH, NW, NC, NE (post-1981); and at IP, EC (pre-1981); however, with Sheffield data, maximum grids in all homogeneous regions are exhibiting spatially coherent significant increasing trend during the post-1981 and 1951-2012 periods. The spatially coherent significant decreasing trend in both IMD and Sheffield data is observed at NW, NC, and 
NE (pre-1981). In both IMD and Sheffield data, compared to the pre-1981 and 1951-2012 period, the percentage of grids showing a significant increasing (decreasing) trend is more (less) in the post-1981 period. Contrasting trend results are also observed with IMD and Sheffield datasets. IMD dataset shows a significant decreasing trend in few grids at IP, WC, NE (pre-1981); and at NC, IP (1951-2012); however, the Sheffield dataset shows a significant increasing trend. The spatially coherent significant increasing trend is observed in maximum grids at WH (pre-1981 and 1951-2012); at IP, EC (post-1981); and at NE (1951-2012) with Sheffield data; however, no trend is observed with IMD data.

TR shows significant increasing trend at 24\% (pre-1981), 69\% (post-1981) and 58\% (1951-2012) grids in IMD data. However, the significant increasing trend of TR in Sheffield data is observed at 47\% (pre-1981), 87\% (post1981), and 85\% (1951-2012) grids. The good agreement between the two datasets, for significant increasing and significant decreasing trend patterns, can be noted during the post-1981 and pre-1981 periods, respectively.

\subsection{Spatial variability and trends in SU}

The spatial distribution of mean SU for the period 1951-2012 shows large spatial variability over pan India in both the datasets analyzed (see Fig. 9a, 9b). The spatial distribution is nearly similar at every homogeneous temperature region except few grids at $\mathrm{WH}, \mathrm{NW}, \mathrm{NC}$, and $\mathrm{NE}$. The maximum and minimum value of mean SU at WH, NW, NC, and NE in IMD data is different from the maximum and minimum value in Sheffield data. For the IMD data, the mean SU value for the pre-1981, post-1981, and 1951-2012 periods is 323.08, 324.90, and 323.99, respectively. However, in Sheffield data, the mean SU value for the pre-1981, post-1981, and 1951-2012 periods is $287.54,290.25$, and 288.90, respectively (see Fig. 9e, 9f). The spatial variance of SU shows an increasing trend during pre-1981 and decreasing trend during post-1981 for IMD. The decreasing trend for the post-1981 period is found statistically significant. The spatial variance in Sheffield data shows a decreasing trend during pre-1981 and an increasing trend during post-1981; however, both the trends are found statistically significant. In IMD data, the spatial variance is higher for the post-1981 period. The spatial variance in Sheffield dataset for both pre-1981and post-1981 is higher compared to the IMD dataset (see Fig. 9c, 9d). The high peak values of spatial variance is observed in the Sheffield dataset compared to the IMD dataset.

In IMD data, the significant increasing trend with good spatial coherence is observed in maximum grids at WH, NE (post-1981 and 1951-2012). However, a spatially coherent significant increasing trend in Sheffield data is observed in most of the grids at NW, NC, IP, and NE (post-1981 \& 1951-2012). In IMD data, fewer grids at WC, IP, NC, NE (pre-1951); and at NE, IP, WC, NC (post-1981 and 1951-2012) show a significant increasing trend with less spatial coherence. The significant decreasing trend with good spatial coherence in IMD is observed in maximum grids at NW and NC (pre-1981); however, with Sheffield data, the majority of grids in NW, NC, NE, and IP (pre-1981) show a spatially coherent significant decreasing trend. In both IMD and Sheffield data, compared to the pre-1981 and 1951-2012 period, the percentage of grids showing a significant increasing (decreasing) trend is more (less) in the post-1981 period. Contrasting trend results are also observed with IMD and Sheffield datasets. The IMD dataset shows a significant increasing trend in maximum grids at WH (post1981); and at NE (pre-1981 and post-1981); however, the Sheffield dataset shows a significant decreasing trend. The IMD dataset shows a significant decreasing trend in few grids at NC (post-1981); and at NE (post-1981 and 1951-2012), while the Sheffield dataset shows a significant increasing trend. The spatially coherent significant increasing trend is observed at WH (pre-1981) with Sheffield data; however, no trend is observed with IMD data.

Figure 8 Mean SU for period 1951-2012 (a) IMD (b) Sheffield ; SU spatial variance over India, asterisk denotes significant trend (at 5\% significance level) (c) IMD (d) Sheffield; SU Box Plot for three time windows (e) IMD

(f) Sheffield ; SU trend (at 5\% significance level) in three time windows for IMD (g)1951-1981 (h)1982-2012

(i)1951-2012, for Sheffield (j)1951-1981 (k)1982-2012 (1)1951-2012; Grids with significant increasing trend, significant decreasing trend, no trend and inconsistent data are shown in red, blue, white and grey color respectively; Pie chart on right side shows percentage of grids having significant increasing, significant decreasing and no trend. 
SU shows significant increasing trend at 15\% (pre-1981), 40\% (post-1981) and 64\% (1951-2012) grids in IMD data. However, the significant increasing trend of SU in Sheffield data is observed at 13\% (pre-1981), 69\% (post1981), and 48\% (1951-2012) grids. Overall, there is mostly disagreement between the two datasets for significant increasing and significant decreasing trend patterns during post-1981 and 1951-2012. A better agreement between the two datasets can be noted, with a significant decreasing trend during the pre-1981 period.

\subsection{Spatial variability and trends in WSDI}

The spatial distribution of mean WSDI for the period 1951-2012 shows less spatial variability over pan India in both the datasets analyzed (see Fig. 10a, 10b). The spatial distribution of both datasets is nearly similar at every homogeneous temperature region. The maximum and minimum value of mean WSDI at different homogeneous regions in IMD data is different from the maximum and minimum in Sheffield data. For the IMD data, the mean WSDI value for the pre-1981, post-1981, and 1951-2012 periods is $8.94,18.86$, and 13.90 , respectively. However, for the Sheffield data, the mean WSDI value for the pre-1981, post-1981, and 1951-2012 period is 6.57, 12.02, and 9.29, respectively (see Fig. 10e, 10f). A lesser mean value is observed in Sheffield data at all three-time windows. For the IMD data, the spatial variance of WSDI shows an increasing trend for the pre-1981 and post1981 periods. The increasing trend for the post-1981 period is found statistically significant. The spatial variance in Sheffield data shows decreasing trend during the pre-1981 period and an increasing trend during the post-1981 period; however, the increasing trend during post-1981 is found statistically significant. The spatial variance is higher for the post-1981 period in both the datasets; however, the high peak values of spatial variance is obtained in the Sheffield data compared to the IMD data (see Fig. 10c, 10d).

Fig 9 Mean WSDI for period 1951-2012 (a) IMD (b) Sheffield ; WSDI spatial variance over India, asterisk denotes significant trend (at 5\% significance level) (c) IMD (d) Sheffield ; WSDI Box Plot for three time windows (e) IMD (f) Sheffield ; WSDI trend (at 5\% significance level) in three time windows for IMD (g)19511981 (h)1982-2012 (i)1951-2012, for Sheffield (j)1951-1981 (k)1982-2012 (l)1951-2012; Grids with significant increasing trend, significant decreasing trend, no trend and inconsistent data are shown in red, blue, white and grey color respectively; Pie chart on right side shows percentage of grids having significant increasing, significant decreasing and no trend.

The trend pattern of WSDI in Sheffield data is distinct from the trend pattern in IMD data except for the post1981 period. In IMD data, a significant increasing trend with good spatial coherence is observed in the majority of grids at every homogeneous region during post-1981 and 1951-2012. However, in Sheffield data spatially coherent significant increasing trend is observed at NW, NC, IP, WC, and EC (post-1981 \& 1951-2012). A few grids at IP, WC, and EC (pre-1981) also shows a significant increasing trend with good spatial coherence with IMD data while the significant increasing trend observed in few grids at WH, NC, IP, and WC (pre-1981) with Sheffield data is spatially less coherent. The significant decreasing trend in IMD data is observed in fewer grids at WH, NW, NC, NE, and WC (pre-1981); however, in Sheffield data, the significant decreasing trend is observed at WH, IP, WC, NW, and NE (pre-1981). In both IMD and Sheffield, compared to pre-1981 and 1951-2012 periods, the percentage of grids showing a significant increasing (decreasing) trend is more (less) in the post-1981 period. Contrasting trend result is also observed with IMD and Sheffield datasets. IMD dataset shows a significant increasing trend in few grids at EC (post-1981); and at WC, IP, NE (1951-2012); however, the Sheffield dataset shows a significant decreasing trend.

WSDI shows a predominant significant increasing trend at 87\% (post-1981) and 78\% (1951-2012) grids in IMD data. The past studies have also confirmed the increasing spatial extent of heatwaves across entire India. (Pai et al. 2013; Mishra et al. 2017; Sharma and Mujumdar 2017). Also, in Sheffield data, the WSDI shows a similar predominant significant increasing trend at 78\% (post-1981) and 50\% (1951-2012) grids. A better agreement between the two datasets can be noted, with a significant increasing trend during the post-1981 and 1951-2012 period.

\subsection{Spatial variability and trends in CSDI}

The spatial distribution of mean CSDI for the period 1951-2012 shows less spatial variability over pan India for both the datasets analyzed (see Fig. 11a, 11b). Though spatial distribution is nearly similar for both datasets in all the regions, a slight difference is observed in few grids at NC, NW, and IP. The maximum and minimum value of 
mean CSDI at NC, NW, and IP in IMD data is significantly different compared to the maximum and minimum value in Sheffield data. In IMD data, the mean CSDI value for the pre-1981, post-1981, and 1951-2012 period is $6.43,5.34$, and 5.88, respectively. However, in Sheffield data, the mean CSDI value for pre-1981, post-1981, and 1951-2012 period is 4.80, 2.15, and 3.48, respectively (see Fig. 11e, 11f). A lesser value of mean CSDI is observed with Sheffield data for all the three-time window. The spatial variance of CSDI shows an increasing trend during pre-1981 and decreasing trend during post-1981 for the IMD dataset. However, these trends are found statistically non-significant. In the Sheffield dataset, the spatial variance of CSDI shows a statistically significant decreasing trend during pre-1981 and post-1981. In IMD data, the spatial variance is higher for the post-1981 period, while in the Sheffield data pre-1981 period shows higher spatial variance (see Fig. 11c, 11d). The high peak values of spatial variance is observed in the IMD dataset compared to the Sheffield dataset.

The trend pattern of CSDI in Sheffield data is distinct from the trend pattern in IMD data. In the IMD data, the significant increasing trend of CSDI is observed in few scattered grids at WH, NW, NC, NE, WC, IP (pre-1981); at IP (post-1982); and at WC, IP, NC (1951-2012). However, in Sheffield data, a significant increasing trend is observed in few scattered grids at WH, NW, NC, NE, WC, IP (pre-1981); at NW, NE, EC (post-1982); and at WC, NW, NC (1951-2012). With IMD data, the significant decreasing trend with good spatial coherence is observed in most grids at NW, NC, and NE (post-1981). However, with Sheffield data, the significant decreasing trend with good spatial coherence is observed in maximum grids at NC, IP, EC (post-1981); at WH, NW, NC, IP, NE (post-1982); and at WH, NW, NC, IP, NE, WC (1951-2012). In IMD data, compared to the pre-1981 and 1951-2012 period, the percentage of grids showing a significant increasing (decreasing) trend is less (more) in the post-1981 period.

Fig. 10 Mean CSDI for period 1951-2012 (a) IMD (b) Sheffield ; CSDI spatial variance over India, asterisk denotes significant trend (at 5\% significance level) (c) IMD (d) Sheffield ; CSDI Box Plot for three time windows (e) IMD (f) Sheffield ; CSDI trend (at 5\% significance level) in three time windows for IMD (g)19511981 (h)1982-2012 (i)1951-2012, for Sheffield (j)1951-1981 (k)1982-2012 (l)1951-2012; Grids with significant increasing trend, significant decreasing trend, no trend and inconsistent data are shown in red, blue, white and grey color respectively; Pie chart on right side shows percentage of grids having significant increasing, significant decreasing and no trend.

CSDI shows a predominant significant decreasing trend in IMD as well as Sheffield data in all three-time windows. Nearly $15 \%$ (pre-1981), 32\% (post-1981) and 26\% (1951-2012) grids points in IMD data; and 25\% (pre-1981), 33\% (post-1981), 52\% (1951-2012) grids in Sheffield data shows significant decreasing trend. The earlier studies have confirmed the significant increase in frequency and spatial coverage of cold wave (CW) and severe cold wave (SCW) in north India during 1971-2000 (Pai et al. 2004). Overall, there is mostly disagreement between the two datasets for significant increasing and significant decreasing trend patterns during pre-1981 and 1951-2012. A better agreement between the two datasets can be noted, with a significant decreasing trend in few grids at WH, NW, and NC (post-1981).

\subsection{Comparison of Observed and Reanalysis dataset}

Gridded observational datasets are based on daily observations of in situ stations that generally lack spatial coverage, whereas; the gridded reanalysis dataset is based on assimilating observational data into atmospheric models. Reanalysis datasets provides better spatial and temporal coverage compared to observational datasets therefore; reanalysis datasets are widely used for global as well as regional level studies. The global-scale comparisons of the reanalysis products for precipitation and temperature is reported in many studies (Simmons et al. 2004, 2010; Bosilovich et al. 2008; Donat et al. 2014). For India, few studies compare reanalysis datasets with the observational datasets based on climatological variations (Misra et al. 2012; Rana et al. 2015; Kishore et al. 2016; Ghodichore et al. 2018). Sheffield reanalysis dataset is compared against the IMD dataset for the extreme temperature indices. The spatial distribution of mean of extreme indices is captured reasonably well by Sheffield dataset. However, the significant decreasing trend of TX10p (at NC) and TN10p (at pan India) during 1951-2012 period is overestimated by Sheffield dataset. The underestimation in significant increasing trend of TX90p (at NW, NC, IP) and WSDI (at IP) is also observed during different time windows. Even for TN90p and TR, Sheffield data detected contrasting significant increasing trend over fewer grids at IP during pre-1981 and post-1981 period. In case of WSDI, Sheffield dataset failed to detect significant increasing trend at NE (during post-1981 and 1951- 
2012) and at WH (1951-2012). The past studies also reported that the reanalysis datasets failed to capture the trend pattern and overestimated/underestimated the trend pattern compared to the observational dataset. Shah and Mishra, (2014) reported that reanalysis products showed a high warm bias in the monsoon season temperature in northwestern India and parts of the Gangetic Plain, and a high cold bias in the Kashmir and southern peninsula regions. Ghodichore et al., 2018 found that reanalysis dataset (CFSR and MERRA-L) overestimated (underestimated) the high (low) temperatures over the northwestern (southeastern) regions of India. Kumar et al., (2020) found that trend pattern of reanalysis (Climate Prediction Centre, CPC) and observed (IMD) dataset for temperature extremes over India are nearly similar for period 1971-2013. The studies on global reanalysis datasets reported that temperature dataset is strongly affected by atmospheric boundary layer turbulence, the land surface scheme followed in the reanalysis (Wang and Zeng 2013) and there is large undesirable and nonphysical biases in reanalysis datasets which limit their ability to capture long-term trends (Bosilovich et al. 2008). Overall, the reanalysis dataset has large bias due to inhomogeneity in input observational data, imperfections in data assimilation methods and atmospheric model uncertainties (Bengtsson et al., 2004; Thorne \& Vose, 2010) and should be used be cautiously used for long term climate assessment.

\section{Conclusions}

The present study focuses on the analysis of spatiotemporal variations and trends in the temperature extremes over India, for the period from 1951 to 2012 , using $0.25^{\circ} \times 0.25^{\circ}$ high-resolution daily temperature data. Further, Sheffield gridded temperature dataset is compared with $1^{\circ} \times 1^{\circ}$, gridded temperature dataset of Indian Meteorological Department (IMD). Conclusions drawn from this study are summarized below.

- Both IMD and Sheffield datasets showed similar spatial distribution for mean - Tmax, Tmin, DTR, TX90p, TR, WSDI and slightly different spatial distribution for mean -TX10p, TN10p, TN90p, SU, CSDI over pan India for period 1951-2012.

- Both dataset reported significant differences in spatial variance for all extreme temperature indices during pre-1981 and post-1981 periods.

- DTR trend pattern of IMD and Sheffield data in all three time windows varied significantly. However, grids at IP, WC and EC had shown similarity with significant increasing trends during the post-1981 and 1951-2012 periods.

- Trend analysis of TX10p and TN10p for Sheffield data showed an overestimation of decreasing trend at $\mathrm{NC}$ and Pan India respectively.

- For TX90p, Sheffield data underestimated significant increasing trend at NW, NC and IP and overestimated at WH during pre-1981. However, both datasets showed good similarity with significant increasing trends for the post-1981 and 1951-2012 period.

- For TN90p and TR, Sheffield data detected a false significant increasing trend at fewer grids at IP during pre-1981 and post-1981 periods.

- For SU, Sheffield data overestimated significant increasing trends at NW and NC and underestimated at NE during the post-1981 and 1951-2012 period. The false detection of significant increasing trend with Sheffield data is found at WH during pre-1981.

- For WSDI, both data showed similarity in significant increasing trend pattern during post-1981. However, Sheffield data underestimated significant increasing trends at IP in all three time windows and failed to detect a significant increasing trend at NE (during post-1981 and 1951-2012) and at WH (19512012).

- In the case of CSDI, the overestimation of significant decreasing trend patterns is observed with Sheffield data in all three-time windows. Additionally, a similarity in trend pattern, between both data, is observed with significant decreasing trend during post-1981 period.

- For both datasets, the probability density function (PDF) of the pooled mean of indices is found statistically significant for DTR, TX10p, TN10p, TX90p, TN90p, TR, SU, WSDI and CSDI (refer Figure S1). 
This study identified the differences in spatial distribution, statistical relation and trend pattern of extreme temperature indices computed using gridded temperature dataset of IMD and Sheffield. This study will provide useful insight to the researchers who plan to use Sheffield dataset in climatological modeling and predictions.

Conflicts of interest/Competing interests: Author declares no conflict of interest.

Funding: No funding is applicable.

Authors' contributions: Corresponding author declares that Anurag has done the analysis, Nitin and Deepak has compiled and edited the manuscript.

Availability of data and material: The data utilised in this manuscript is available at Indian Meteorological Department website at: https://mausam.imd.gov.in/

Code availability: Not Applicable.

Ethics approval: Not Applicable.

Consent to participate: Not Applicable

Consent for publication: Not Applicable

References

Abatzoglou JT (2013) Development of gridded surface meteorological data for ecological applications and modelling. Int J Climatol. https://doi.org/10.1002/joc.3413

Aggarwal PK, Singh AK (2010) Implications of Global Climatic Change on Water and Food Security. In: Water Resources Development and Management

Alexander L, Herold N (2016) ClimPACT2. Indices and software. A document prepared on behalf of The Commission for Climatology $(\mathrm{CCl})$ Expert Team on Sector-Specific Climate Indices (ET-SCI). 46

Alexander L V., Zhang X, Peterson TC, et al (2006) Global observed changes in daily climate extremes of temperature and precipitation. J Geophys Res Atmos. https://doi.org/10.1029/2005JD006290

Andrade C, Leite SM, Santos JA (2012) Temperature extremes in Europe: Overview of their driving atmospheric patterns. Nat Hazards Earth Syst Sci. https://doi.org/10.5194/nhess-12-1671-2012

Anghileri D, Pianosi F, Soncini-Sessa R (2014) Trend detection in seasonal data: From hydrology to water resources. J Hydrol. https://doi.org/10.1016/j.jhydrol.2014.01.022

Bayley G V., Hammersley JM (1946) The "Effective" Number of Independent Observations in an Autocorrelated Time Series. Suppl to J R Stat Soc. https://doi.org/10.2307/2983560

Behnke R, Vavrus S, Allstadt A, et al (2016) Evaluation of downscaled, gridded climate data for the conterminous United States. Ecol Appl. https://doi.org/10.1002/15-1061

Bengtsson L, Hagemann S, Hodges KI (2004) Can climate trends be calculated from reanalysis data? J Geophys Res D Atmos. https://doi.org/10.1029/2004JD004536

Bosilovich MG, Chen J, Robertson FR, Adler RF (2008) Evaluation of global precipitation in reanalyses. J Appl Meteorol Climatol. https://doi.org/10.1175/2008JAMC1921.1

Caldwell P, Chin HNS, Bader DC, Bala G (2009) Evaluation of a WRF dynamical downscaling simulation over California. Clim Change. https://doi.org/10.1007/s10584-009-9583-5

Choi G, Collins D, Ren G, et al (2009) Changes in means and extreme events of temperature and precipitation in the Asia-Pacific Network region, 1955-2007. Int J Climatol. https://doi.org/10.1002/joc.1979 
Cosgrove BA, Lohmann D, Mitchell KE, et al (2003) Real-time and retrospective forcing in the North American Land Data Assimilation System (NLDAS) project. J Geophys Res Atmos. https://doi.org/10.1029/2002jd003118

Dash SK, Hunt JCR (2007) Variability of climate change in India. Curr. Sci.

Dash SK, Jenamani RK, Kalsi SR, Panda SK (2007) Some evidence of climate change in twentieth-century India. Clim Change. https://doi.org/10.1007/s10584-007-9305-9

Dash SK, Mamgain A (2011) Changes in the frequency of different categories of temperature extremes in India. J Appl Meteorol Climatol. https://doi.org/10.1175/2011JAMC2687.1

Demaria EMC, Maurer EP, Sheffield J, et al (2013) Using a gridded global dataset to characterize regional hydroclimate in central Chile. J Hydrometeorol. https://doi.org/10.1175/JHM-D-12-047.1

Donat MG, Sillmann J, Wild S, et al (2014) Consistency of temperature and precipitation extremes across various global gridded in situ and reanalysis datasets. J Clim. https://doi.org/10.1175/JCLI-D-13-00405.1

Frich P, Alexander L V., Della-Marta P, et al (2002) Observed coherent changes in climatic extremes during the second half of the twentieth century. Clim Res. https://doi.org/10.3354/cr019193

Ghodichore N, Vinnarasi R, Dhanya CT, Roy SB (2018) Reliability of reanalyses products in simulating precipitation and temperature characteristics over India. J Earth Syst Sci. https://doi.org/10.1007/s12040018-1024-2

Griffiths GM, Chambers LE, Haylock MR, et al (2005) Change in mean temperature as a predictor of extreme temperature change in the Asia-Pacific region. Int J Climatol. https://doi.org/10.1002/joc.1194

Hamed KH, Ramachandra Rao A (1998) A modified Mann-Kendall trend test for autocorrelated data. J Hydrol. https://doi.org/10.1016/S0022-1694(97)00125-X

IPCC (2014) Climate Change 2014: Synthesis Report. Contribution of Working Groups I, II and III to the Fifth Assessment Report of the Intergovernmental Panel on Climate Change

IPCC IPOCC (2007) Climate Change 2007 - The Physical Science Basis: Working Group I Contribution to the Fourth Assessment Report of the IPCC. Science (80- ). https://doi.org/volume

Jain SK, Kumar V (2012) Trend analysis of rainfall and temperature data for India. Curr. Sci.

Joshi N, Gupta D, Suryavanshi S, et al (2016) Analysis of trends and dominant periodicities in drought variables in India: A wavelet transform based approach. Atmos Res. https://doi.org/10.1016/j.atmosres.2016.07.030

Kanamaru H, Kanamitsu M (2007) Fifty-seven-year California reanalysis downscaling at $10 \mathrm{~km}$ (CaRD10). Part II: Comparison with North American regional reanalysis. J Clim. https://doi.org/10.1175/2007JCLI1522.1

Karl TR, Knight RW, Gallo KP, et al (1993) A New Perspective on Recent Global Warming: Asymmetric Trends of Daily Maximum and Minimum Temperature. Bull Am Meteorol Soc. https://doi.org/10.1175/15200477(1993)074<1007:anporg>2.0.co;2

Kishore P, Jyothi S, Basha G, et al (2016) Precipitation climatology over India: validation with observations and reanalysis datasets and spatial trends. Clim Dyn. https://doi.org/10.1007/s00382-015-2597-y

Klein Tank AMG, Peterson TC, Quadir DA, et al (2006) Changes in daily temperature and precipitation extremes in central and south Asia. J Geophys Res Atmos. https://doi.org/10.1029/2005JD006316

Kothawale DR, Munot AA, Kumar KK (2010) Surface air temperature variability over India during 1901-2007, and its association with enso. Clim Res. https://doi.org/10.3354/cr00857 
Kumar S, Chanda K, Pasupuleti S (2020) Spatiotemporal analysis of extreme indices derived from daily precipitation and temperature for climate change detection over India. Theor Appl Climatol. https://doi.org/10.1007/s00704-020-03088-5

Mall RK, Gupta A, Singh R, et al (2006a) Water resources and climate change: An Indian perspective. Curr. Sci.

Mall RK, Singh R, Gupta A, et al (2006b) Impact of climate change on Indian agriculture: A review. Clim. Change

Manton MJ, Della-Marta PM, Haylock MR, et al (2001) Trends in extreme daily rainfall and temperature in southeast Asia and the south Pacific: 1961-1998. Int J Climatol. https://doi.org/10.1002/joc.610

Mishra V, Ganguly AR, Nijssen B, Lettenmaier DP (2015) Changes in observed climate extremes in global urban areas. Environ Res Lett. https://doi.org/10.1088/1748-9326/10/2/024005

Mishra V, Mukherjee S, Kumar R, Stone DA (2017) Heat wave exposure in India in current, $1.5^{\circ} \mathrm{c}$, and $2.0^{\circ} \mathrm{c}$ worlds. Environ Res Lett. https://doi.org/10.1088/1748-9326/aa9388

Mishra V, Shah R, Thrasher B (2014) Soil moisture droughts under the retrospective and projected climate in India. J Hydrometeorol. https://doi.org/10.1175/JHM-D-13-0177.1

Misra V, Pantina P, Chan SC, DiNapoli S (2012) A comparative study of the Indian summer monsoon hydroclimate and its variations in three reanalyses. Clim Dyn. https://doi.org/10.1007/s00382-012-1319-y

Mukherjee S, Mishra V (2018) A sixfold rise in concurrent day and night-time heatwaves in India under $2{ }^{\circ} \mathrm{C}$ warming. Sci Rep. https://doi.org/10.1038/s41598-018-35348-w

Nanditha JS, Van Der Wiel K, Bhatia U, et al (2020) A seven-fold rise in the probability of exceeding the observed hottest summer in India in a 2 C warmer world. Environ Res Lett. https://doi.org/10.1088/17489326/ab7555

Pai DS, Nair SA, Ramanathan AN (2013) Long term climatology and trends of heat waves over India during the recent 50 years (1961-2010). Mausam

Pai DS, Thapliyal V, Kokate PD (2004) Decadal variation in the heat and cold waves over India during 19712000. Mausam

Panda DK, Mishra A, Kumar A, et al (2014) Spatiotemporal patterns in the mean and extreme temperature indices of India, 1971-2005. Int J Climatol. https://doi.org/10.1002/joc.3931

Patakamuri SK, O’Brien N (2019) Package 'modifiedmk' (Version 1.4.0): Modified Versions of Mann Kendall and Spearman's Rho Trend Tests. CRAN

Rana S, Mcgregor J, Renwick J (2015) Precipitation seasonality over the Indian subcontinent: An evaluation of gauge, reanalyses, and satellite retrievals. J Hydrometeorol. https://doi.org/10.1175/JHM-D-14-0106.1

Ratnam J V., Behera SK, Ratna SB, et al (2016) Anatomy of Indian heatwaves. Sci Rep. https://doi.org/10.1038/srep24395

Ravindranath NH, Joshi N V., Sukumar R, Saxena A (2006) Impact of climate change on forests in India. Curr. Sci.

Salas, J. D., Delleur, J. W., Yevjevich, V. \& Lane, W. L., 1980. Applied Modelling of Hydrologic Time Series, Water Resources Publications, Littleton, Co., USA.

Shah R, Mishra V (2014) Evaluation of the Reanalysis Products for the Monsoon Season Droughts in India. J Hydrometeorol. https://doi.org/10.1175/jhm-d-13-0103.1 
Sharma A, Goyal MK (2020) Assessment of the changes in precipitation and temperature in Teesta River basin in Indian Himalayan Region under climate change. Atmos Res. https://doi.org/10.1016/j.atmosres.2019.104670

Sharma PJ, Loliyana VD, Resmi SR, et al (2018) Spatiotemporal trends in extreme rainfall and temperature indices over Upper Tapi Basin, India. Theor Appl Climatol. https://doi.org/10.1007/s00704-017-2343-y

Sharma S, Mujumdar P (2017) Increasing frequency and spatial extent of concurrent meteorological droughts and heatwaves in India. Sci Rep. https://doi.org/10.1038/s41598-017-15896-3

Sheffield J, Goteti G, Wood EF (2006) Development of a 50-year high-resolution global dataset of meteorological forcings for land surface modeling. J Clim. https://doi.org/10.1175/JCLI3790.1

Sheffield J, Wood EF (2007) Characteristics of global and regional drought, 1950-2000: Analysis of soil moisture data from off-line simulation of the terrestrial hydrologic cycle. $\mathbf{J}$ Geophys Res Atmos. https://doi.org/10.1029/2006JD008288

Sheffield J, Wood EF, Roderick ML (2012) Little change in global drought over the past 60 years. Nature. https://doi.org/10.1038/nature11575

Shepard D (1968) A two-dimensional interpolation function for irregularly-spaced data. In: Proceedings of the 1968 23rd ACM National Conference, ACM 1968

Simmons AJ, Jones PD, da Costa Bechtold V, et al (2004) Comparison of trends and low-frequency variability in CRU, ERA-40, and NCEP/NCAR analyses of surface air temperature. J Geophys Res D Atmos. https://doi.org/10.1029/2004JD005306

Simmons AJ, Willett KM, Jones PD, et al (2010) Low-frequency variations in surface atmospheric humidity, temperature, and precipitation: Inferences from reanalyses and monthly gridded observational data sets. J Geophys Res Atmos. https://doi.org/10.1029/2009JD012442

Stefanova L, Misra V, Chan S, et al (2012) A proxy for high-resolution regional reanalysis for the Southeast United States: Assessment of precipitation variability in dynamically downscaled reanalyses. Clim Dyn. https://doi.org/10.1007/s00382-011-1230-y

Sterl A, Severijns C, Dijkstra H, et al (2008) When can we expect extremely high surface temperatures? Geophys Res Lett. https://doi.org/10.1029/2008GL034071

Suryavanshi S, Pandey A, Chaube UC, Joshi N (2014) Long-term historic changes in climatic variables of Betwa Basin, India. Theor Appl Climatol. https://doi.org/10.1007/s00704-013-1013-y

Tao H, Fraedrich K, Menz C, Zhai J (2014) Trends in extreme temperature indices in the Poyang Lake Basin, China. Stoch Environ Res Risk Assess. https://doi.org/10.1007/s00477-014-0863-X

Thorne PW, Vose RS (2010) Reanalyses suitable for characterizing long-term trends. Bull Am Meteorol Soc. https://doi.org/10.1175/2009BAMS2858.1

Troy TJ, Sheffield J, Wood EF (2011) Estimation of the terrestrial water budget over Northern Eurasia through the use of multiple data sources. J Clim. https://doi.org/10.1175/2011JCLI3936.1

Vinnarasi R, Dhanya CT (2019) Quantifying the shifts and intensification in the annual cycles of diurnal temperature extremes for human comfort and crop production. Environ Res Lett. https://doi.org/10.1088/1748-9326/ab0fe5

Vinnarasi R, Dhanya CT, Chakravorty A, Aghakouchak A (2017) Unravelling Diurnal Asymmetry of Surface Temperature in Different Climate Zones. Sci Rep. https://doi.org/10.1038/s41598-017-07627-5 
Walton DB, Sun F, Hall A, Capps S (2015) A hybrid dynamical-statistical downscaling technique. Part I: Development and validation of the technique. J Clim. https://doi.org/10.1175/JCLI-D-14-00196.1

Wang A, Lettenmaier DP, Sheffield J (2011) Soil moisture drought in China, 1950-2006. J Clim. https://doi.org/10.1175/2011JCLI3733.1

Wang A, Zeng X (2013) Development of global hourly 0.58 land surface air temperature datasets. J Clim. https://doi.org/10.1175/JCLI-D-12-00682.1

Xia Y, Mitchell K, Ek M, et al (2012) Continental-scale water and energy flux analysis and validation for North American Land Data Assimilation System project phase 2 (NLDAS-2): 2. Validation of model-simulated streamflow. J Geophys Res Atmos. https://doi.org/10.1029/2011JD016051

Yue S, Wang CY (2004) The Mann-Kendall test modified by effective sample size to detect trend in serially $\begin{array}{lllll}\text { correlated hydrological } & \text { series. } & \text { Water }\end{array}$ https://doi.org/10.1023/B:WARM.0000043140.61082.60

Zhang X, Aguilar E, Sensoy S, et al (2005) Trends in Middle East climate extreme indices from 1950 to 2003. J Geophys Res Atmos. https://doi.org/10.1029/2005JD006181

Zhou Y, Ren G (2011) Change in extreme temperature event frequency over mainland China, 1961-2008. Clim Res. https://doi.org/10.3354/cr01053

Zhu X, Troy TJ (2018) Agriculturally Relevant Climate Extremes and Their Trends in the World's Major Growing Regions. Earth's Futur. https://doi.org/10.1002/2017EF000687 
Table 1 Extreme Temperature Indices (Here TX = Daily Max Temp., TN = Daily Min Temp.)

\begin{tabular}{|c|c|c|c|}
\hline Short name & Long name & Definition & Units \\
\hline DTR & $\begin{array}{l}\text { Daily temperature } \\
\text { range }\end{array}$ & Mean difference between daily TX and daily TN & ${ }^{\circ} \mathrm{C}$ \\
\hline TX10p & Amount of cool days & Percentage of days when TX $<10$ th percentile & $\%$ \\
\hline TN10p & $\begin{array}{l}\text { Amount of cold } \\
\text { nights }\end{array}$ & Percentage of days when $\mathrm{TN}<10$ th percentile & $\%$ \\
\hline TX90p & Amount of hot days & Percentage of days when TX $>$ 90th percentile & $\%$ \\
\hline TN90p & Amount of hot nights & Percentage of days when TN $>$ 90th percentile & $\%$ \\
\hline TR & Tropical nights & Annual number of days when $\mathrm{TN}>20^{\circ} \mathrm{C}$ & days \\
\hline SU & Summer days & Annual number of days when $\mathrm{TX}>25^{\circ} \mathrm{C}$ & days \\
\hline WSDI & $\begin{array}{l}\text { Warm spell } \\
\text { duration } \\
\text { indicator }\end{array}$ & $\begin{array}{c}\text { Annual number of days with at least } 6 \\
\text { consecutive days when TX }>\text { 90th percentile }\end{array}$ & days \\
\hline CSDI & $\begin{array}{l}\text { Cold spell } \\
\text { duration } \\
\text { indicator }\end{array}$ & $\begin{array}{c}\text { Annual number of days with at least } 6 \\
\text { consecutive days when TN }<10 \text { th percentile }\end{array}$ & days \\
\hline
\end{tabular}


Figures
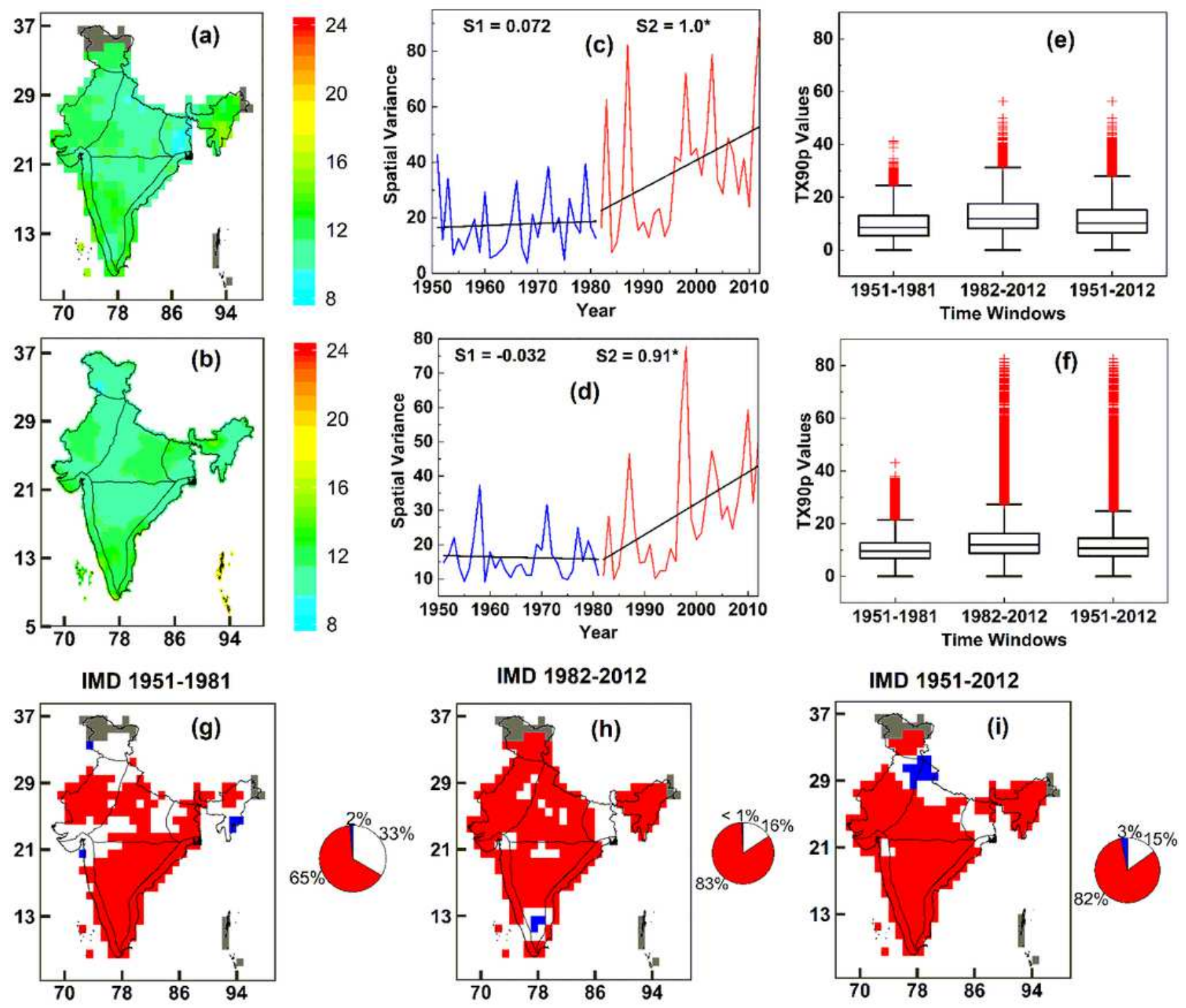

Sheffield 1951-1981
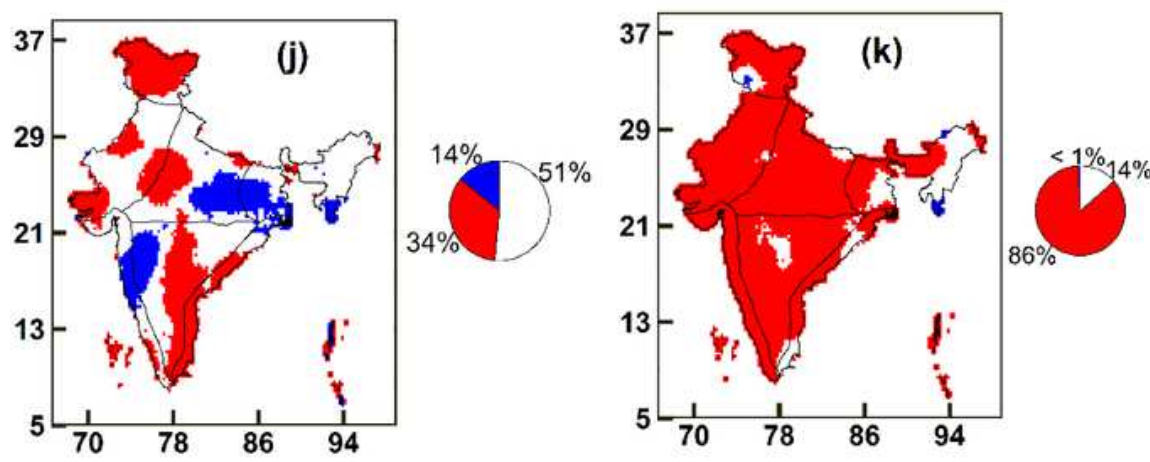

\section{Sheffield 1951-2012}

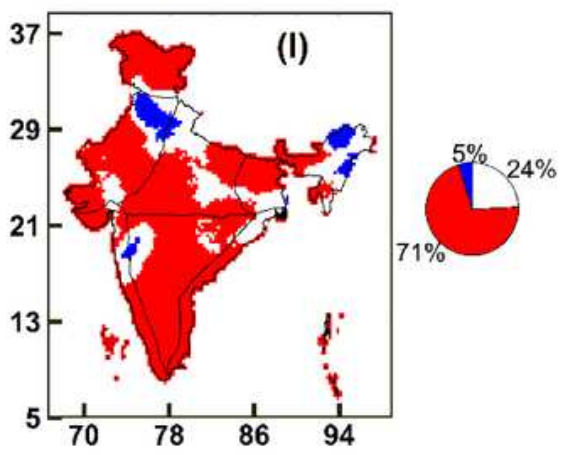

Figure 1

Location map for the study area showing homogeneous temperature regions in India. 

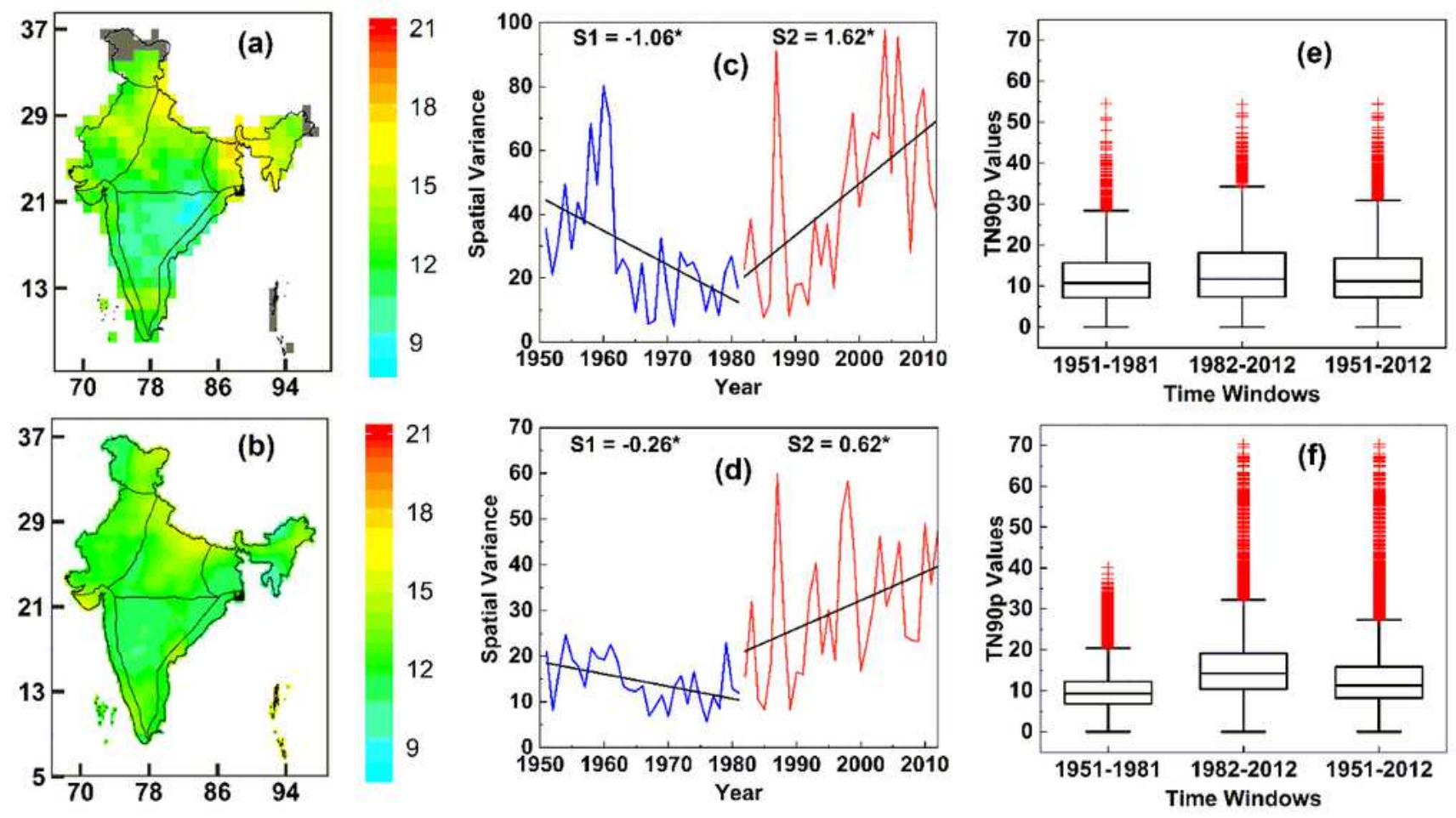

IMD 1951-1981
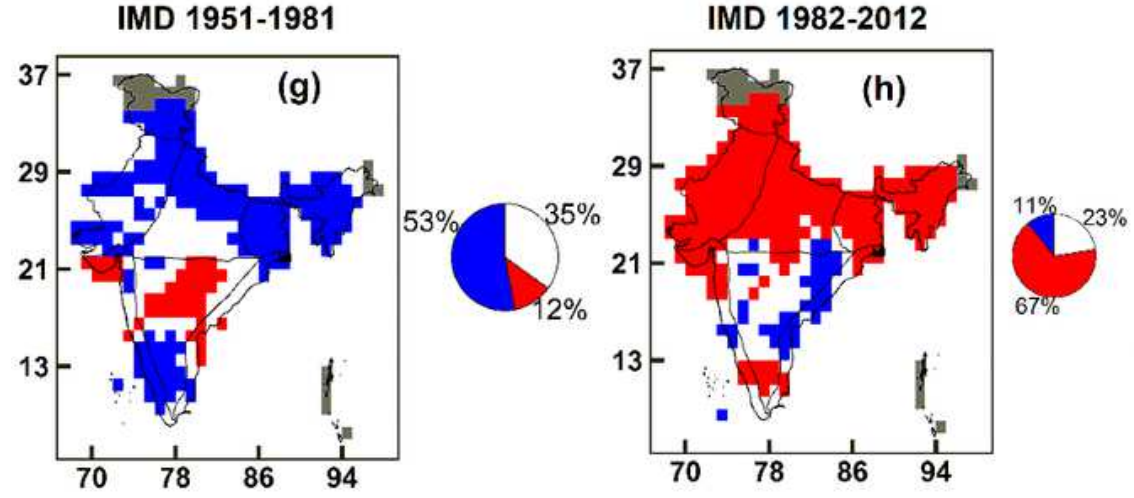

IMD 1951-2012

Sheffield 1951-1981
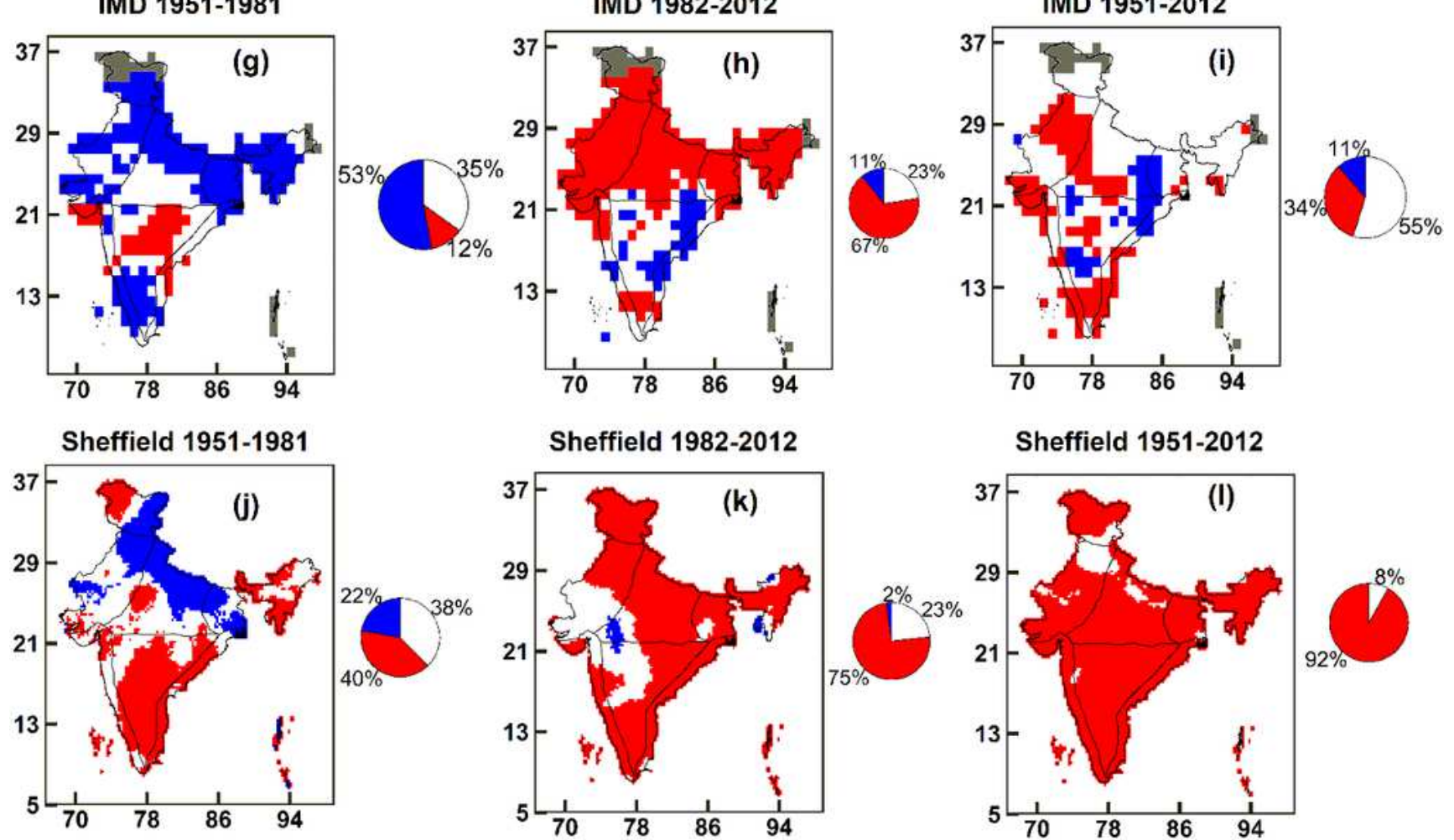

\section{Sheffield 1951-2012}
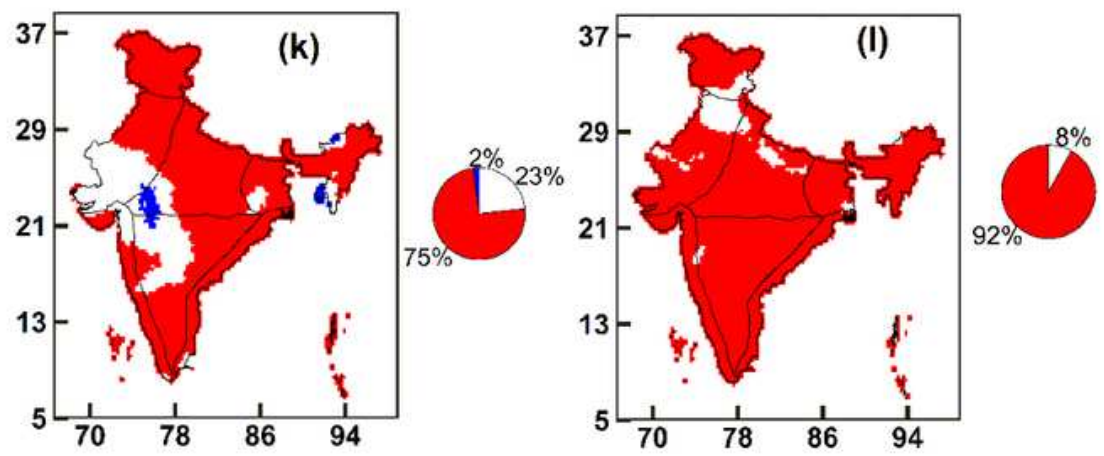

Figure 2

Mean Tmax for period 1951-2012 (a) IMD (c) Sheffield; Mean Tmin for period 1951-2012 (b) IMD (d) Sheffield; Grids with inconsistent data are shown in grey color. Box plot for pooled mean Tmax (e) and mean Tmin (g). Probability density function for pooled mean Tmax (g) and mean Tmin (h); Blue and red color curves represent IMD and Sheffield dataset, respectively. Statistical significance was estimated using the Ranksum and KS tests for mean and distributions of pooled mean data. 

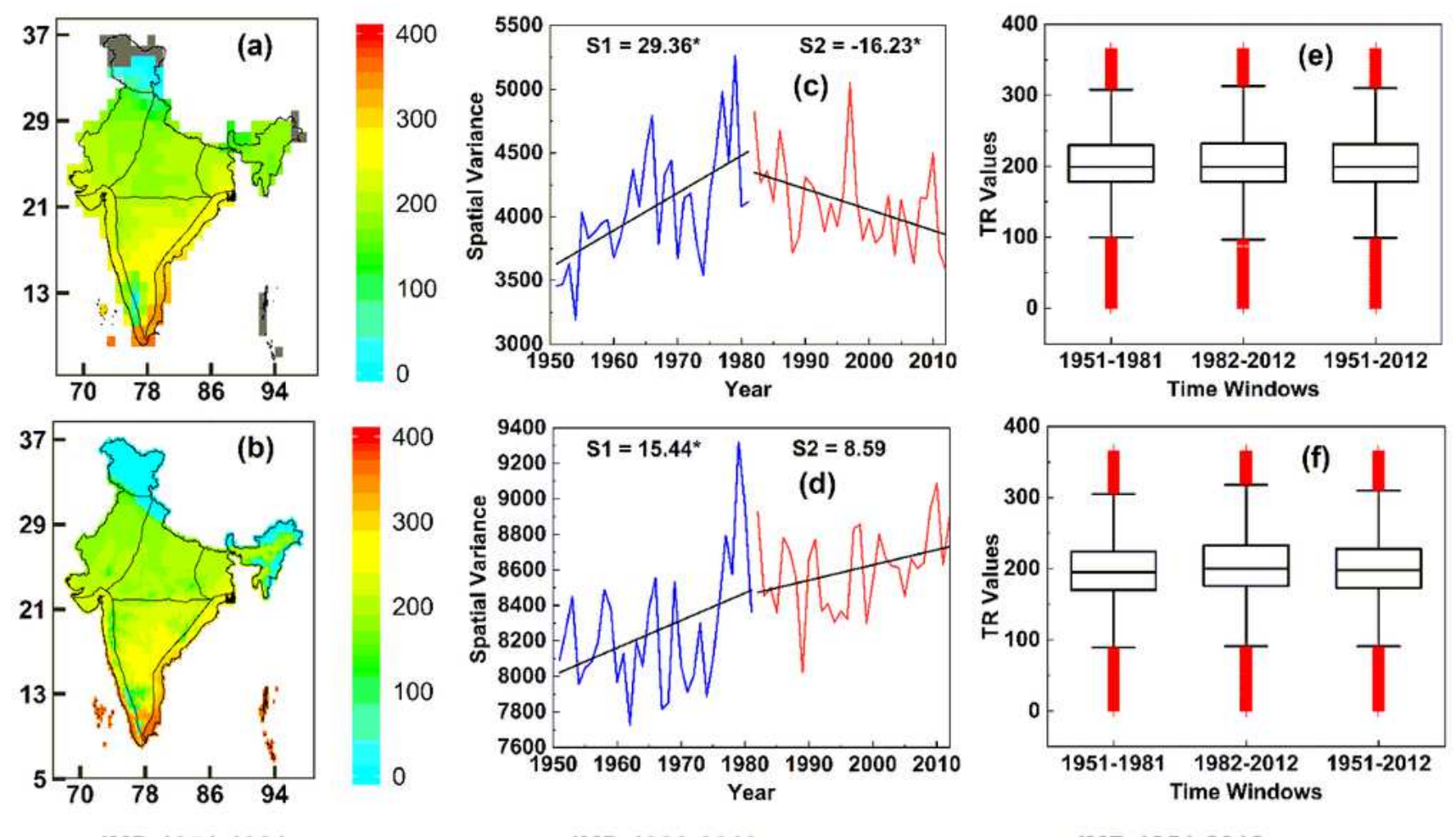

IMD 1951-1981
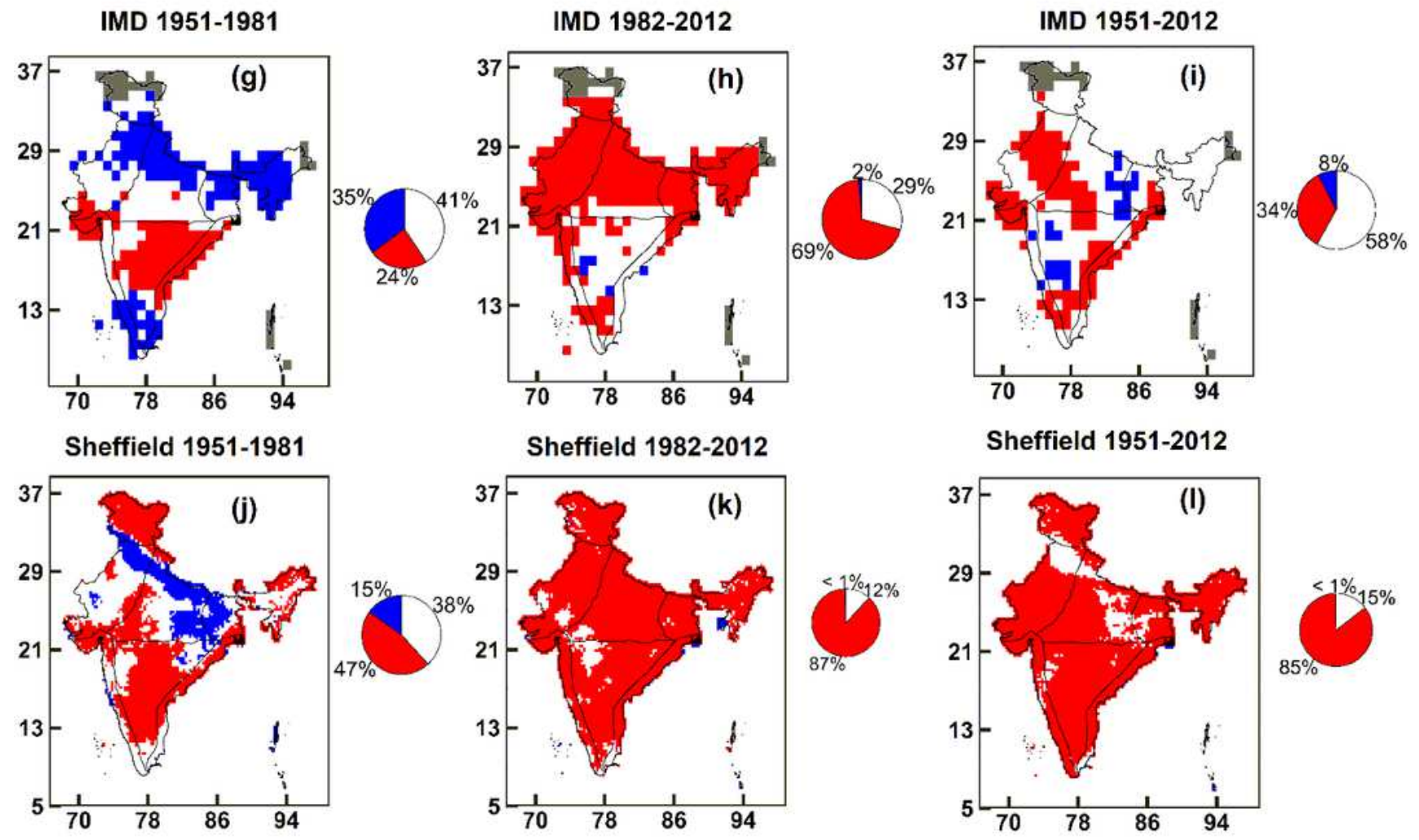

\section{Sheffield 1951-2012}
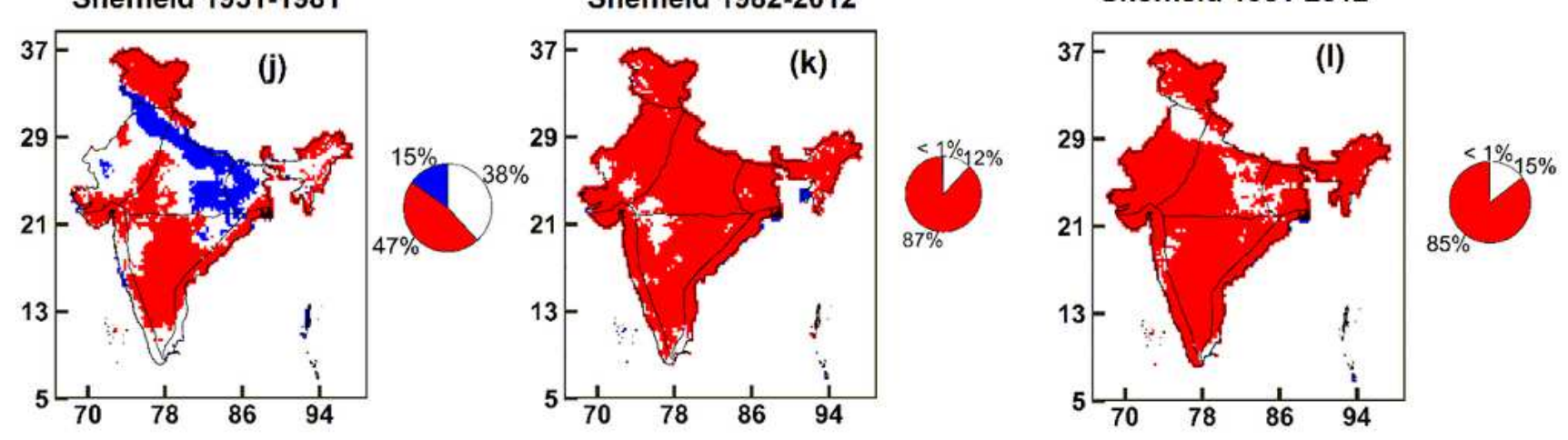

Figure 3

Mean DTR for period 1951-2012 (a) IMD (b) Sheffield ; DTR spatial variance over India, asterisk denotes significant trend (at 5\% significance level) (c) IMD (d) Sheffield; DTR Box Plot for three time windows (e) IMD (f) Sheffield ; DTR trend (at 5\% significance level) in three time windows for IMD (g)1951-1981 (h)1982-2012 (i)1951-2012, for Sheffield (j)1951-1981 (k)1982-2012 (l)1951-2012; Grids with significant increasing trend, significant decreasing trend, no trend and inconsistent data are shown in red, blue, white 
and grey color respectively; Pie chart on right side shows percentage of grids having significant increasing, significant decreasing and no trend.
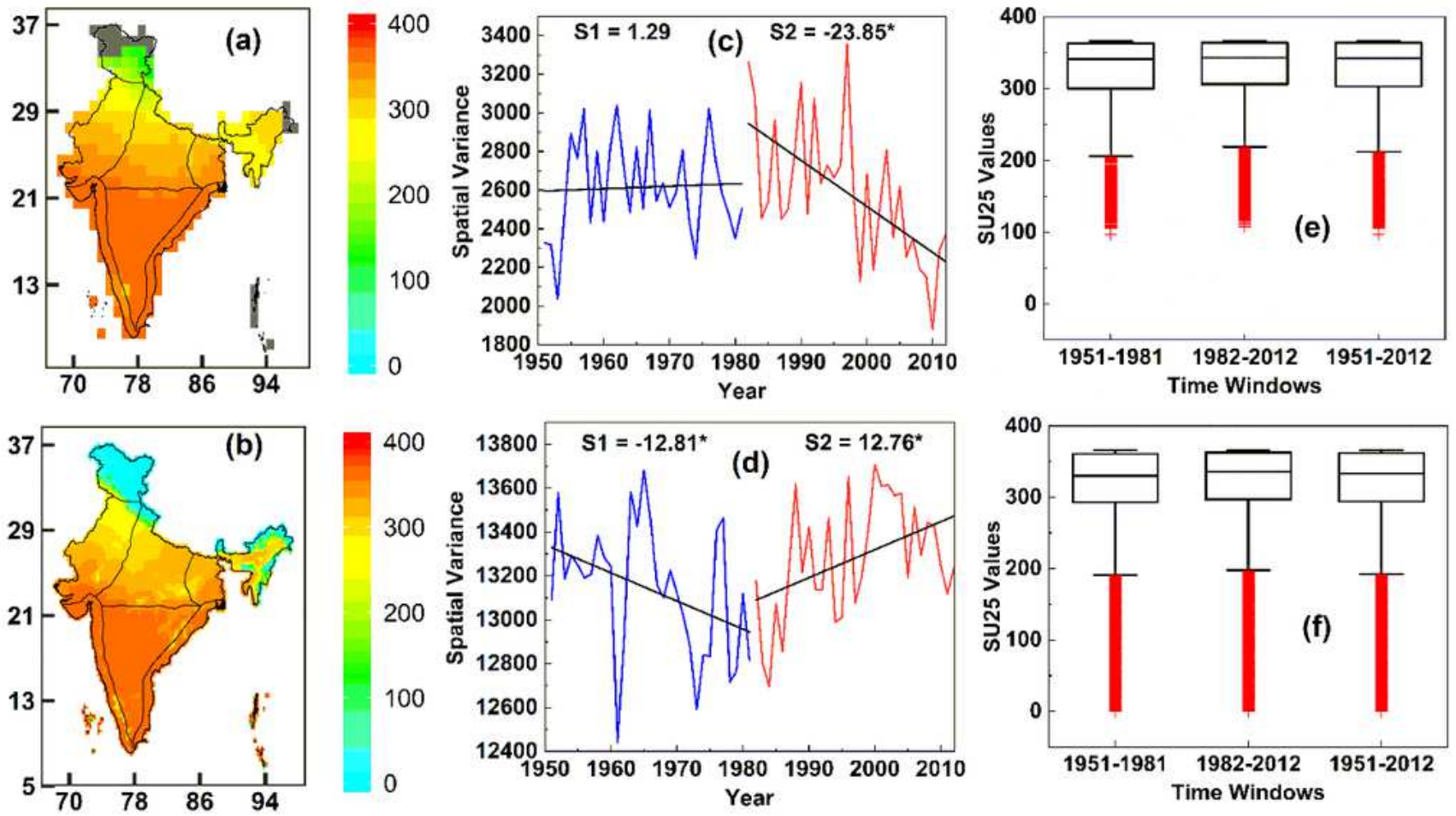

IMD 1951-1981

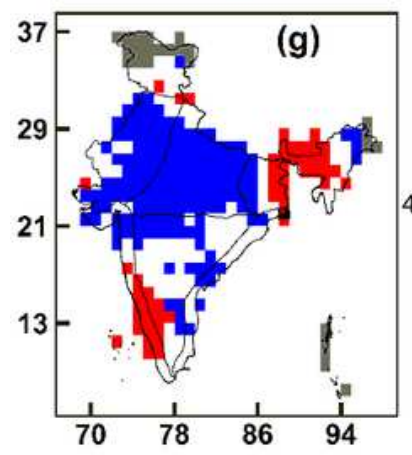

IMD 1982-2012
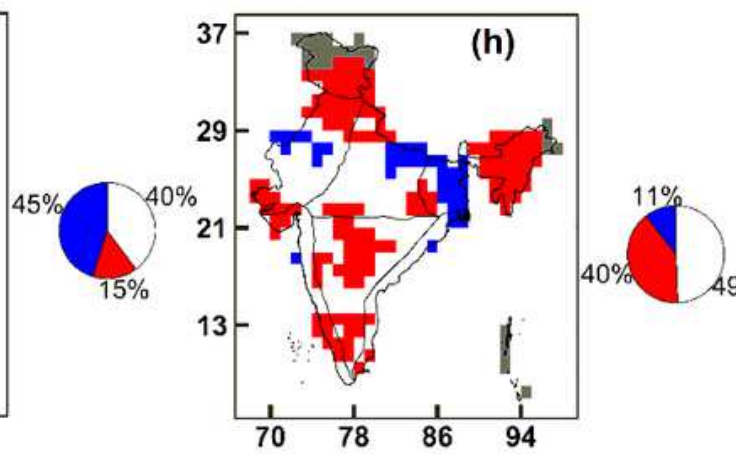

Sheffield 1951-1981

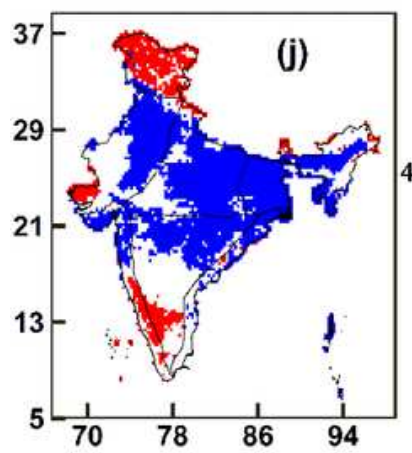

\section{Sheffield 1982-2012}

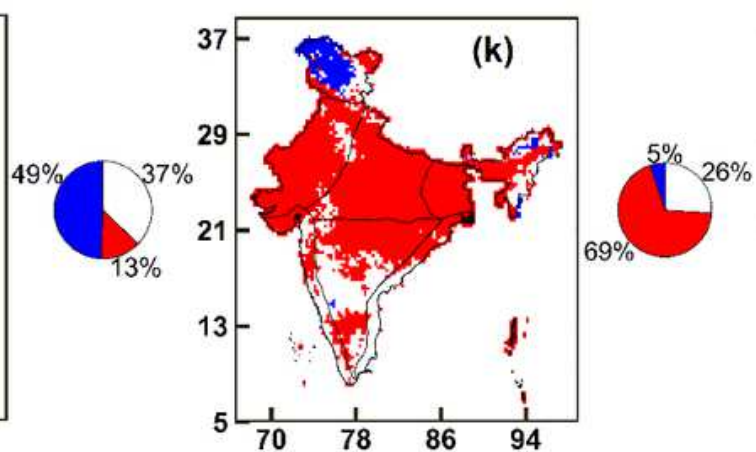

IMD 1951-2012

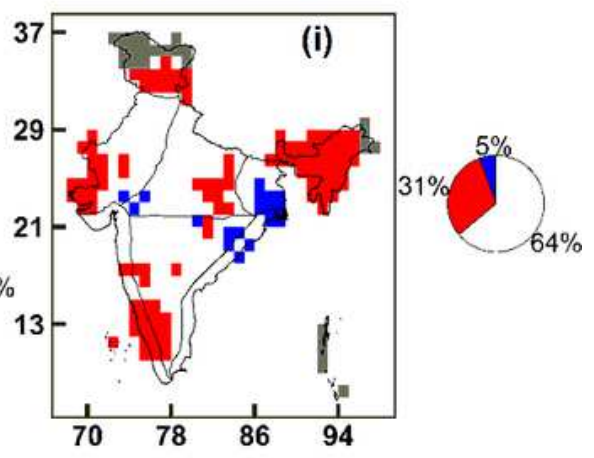

Sheffield 1951-2012

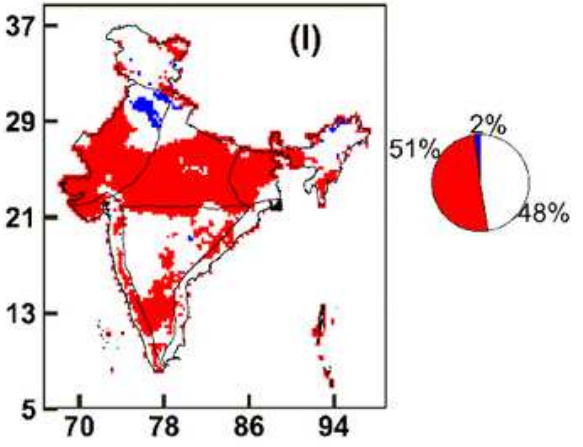

Figure 4

Mean TX10p for period 1951-2012 (a) IMD (b) Sheffield ; TX10p spatial variance over India, asterisk denotes significant trend at 5\% significance level) (c) IMD (d) Sheffield ; TX10p Box Plot for three time windows (e) IMD (f) Sheffield ; TX10p trend (at 5\% significance level) in three time windows for IMD 
(g)1951-1981 (h)1982-2012 (i)1951-2012, for Sheffield (j)1951-1981 (k)1982-2012 (l)1951-2012; Grids with significant increasing trend, significant decreasing trend, no trend and inconsistent data are shown in red, blue, white and grey color respectively; Pie chart on right side shows percentage of grids having significant increasing, significant decreasing and no trend.
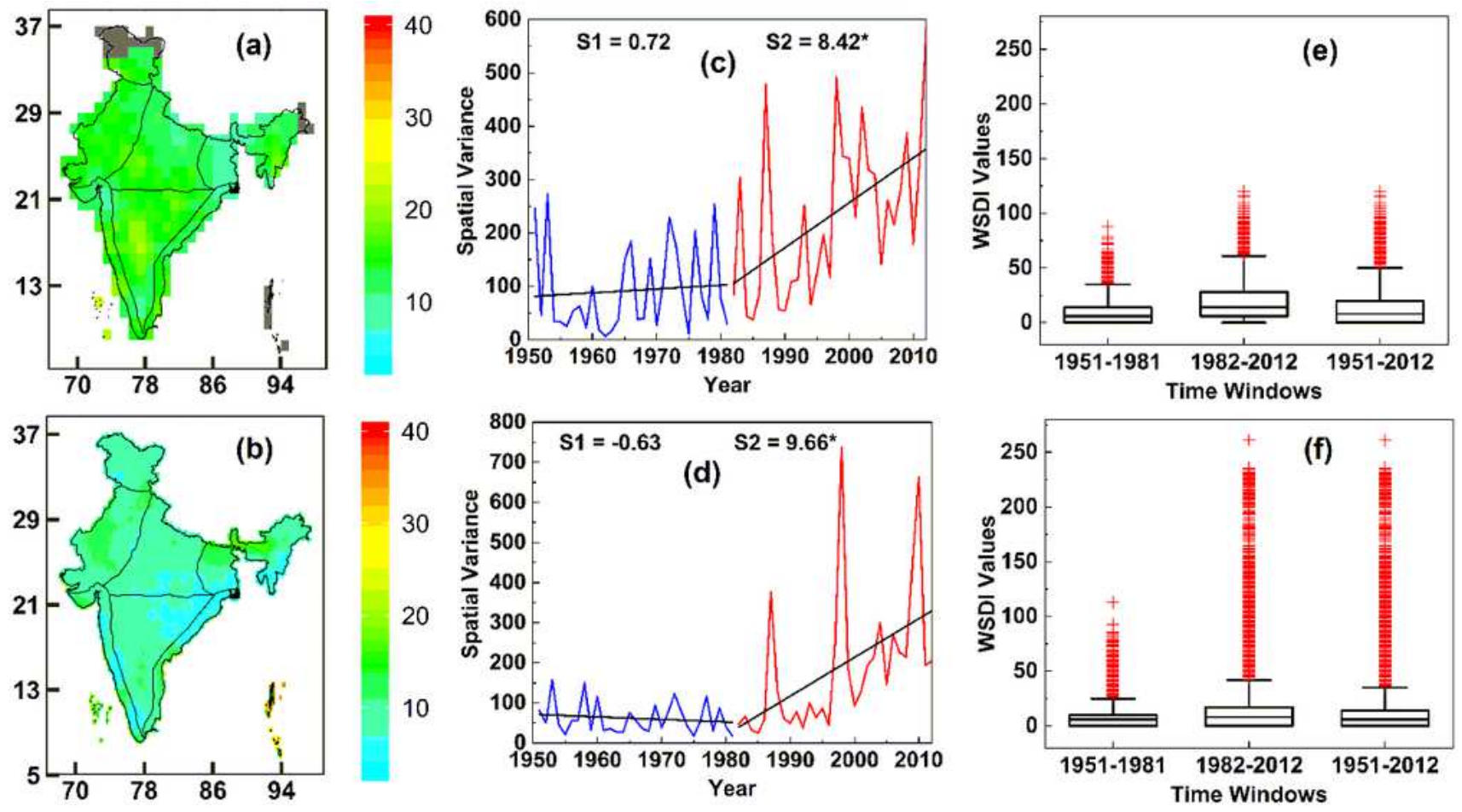

IMD 1951-1981

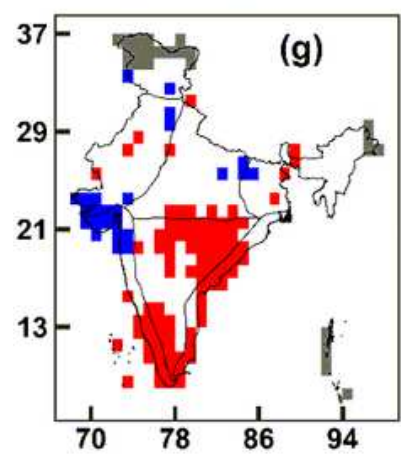

IMD 1982-2012
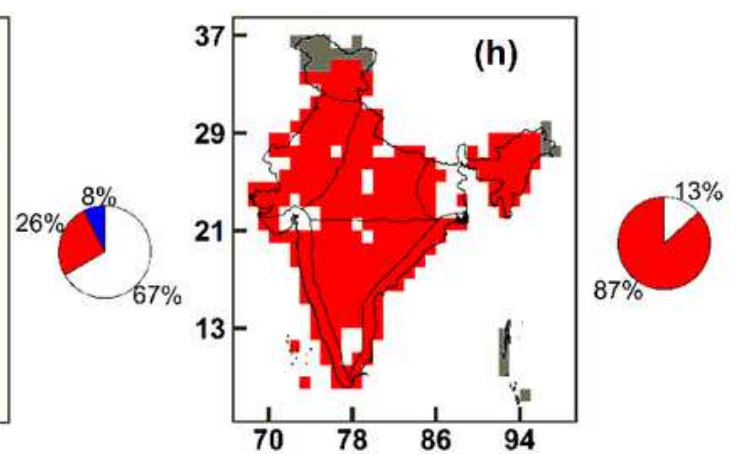

Sheffield 1951-1981

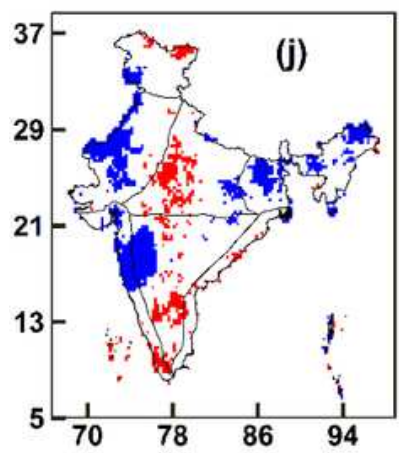

Sheffield 1982-2012
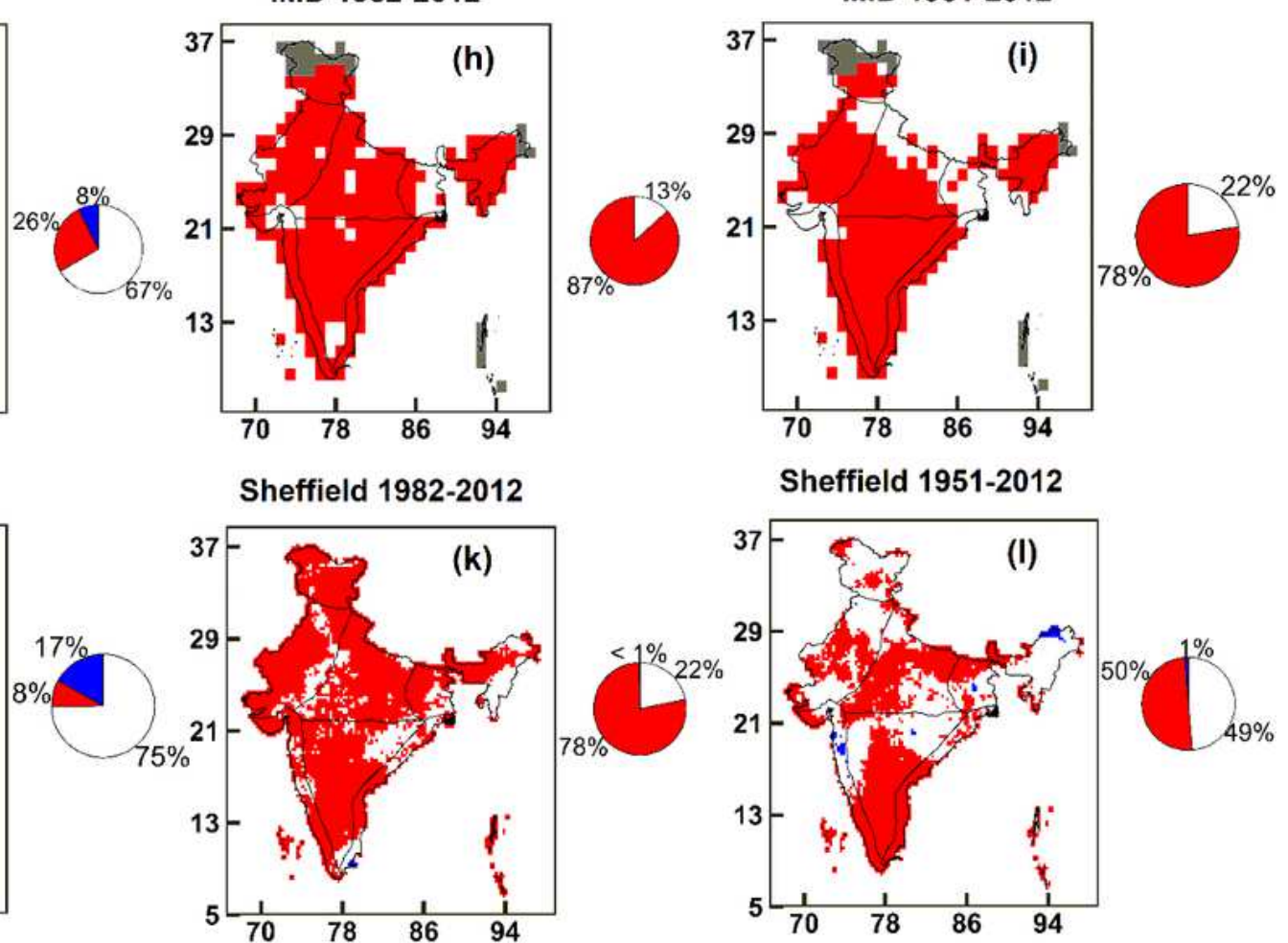

Sheffield 1951-2012

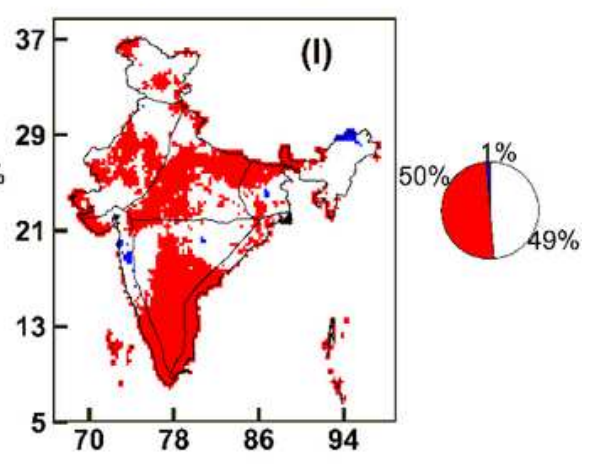

Figure 5 
Mean TN10p for period 1951-2012 (a) IMD (b) Sheffield ; TN10p spatial variance over India, asterisk denotes significant trend (at 5\% significance level) (c) IMD (d) Sheffield; TN10p Box Plot for three time windows (e) IMD (f) Sheffield ; TN10p trend (at 5\% significance level) in three time windows for IMD (g)1951-1981 (h)1982-2012 (i)1951-2012, for Sheffield (j)1951-1981 (k)1982-2012 (l)1951-2012; Grids with significant increasing trend, significant decreasing trend, no trend and inconsistent data are shown in red, blue, white and grey color respectively; Pie chart on right side shows percentage of grids having significant increasing, significant decreasing and no trend.
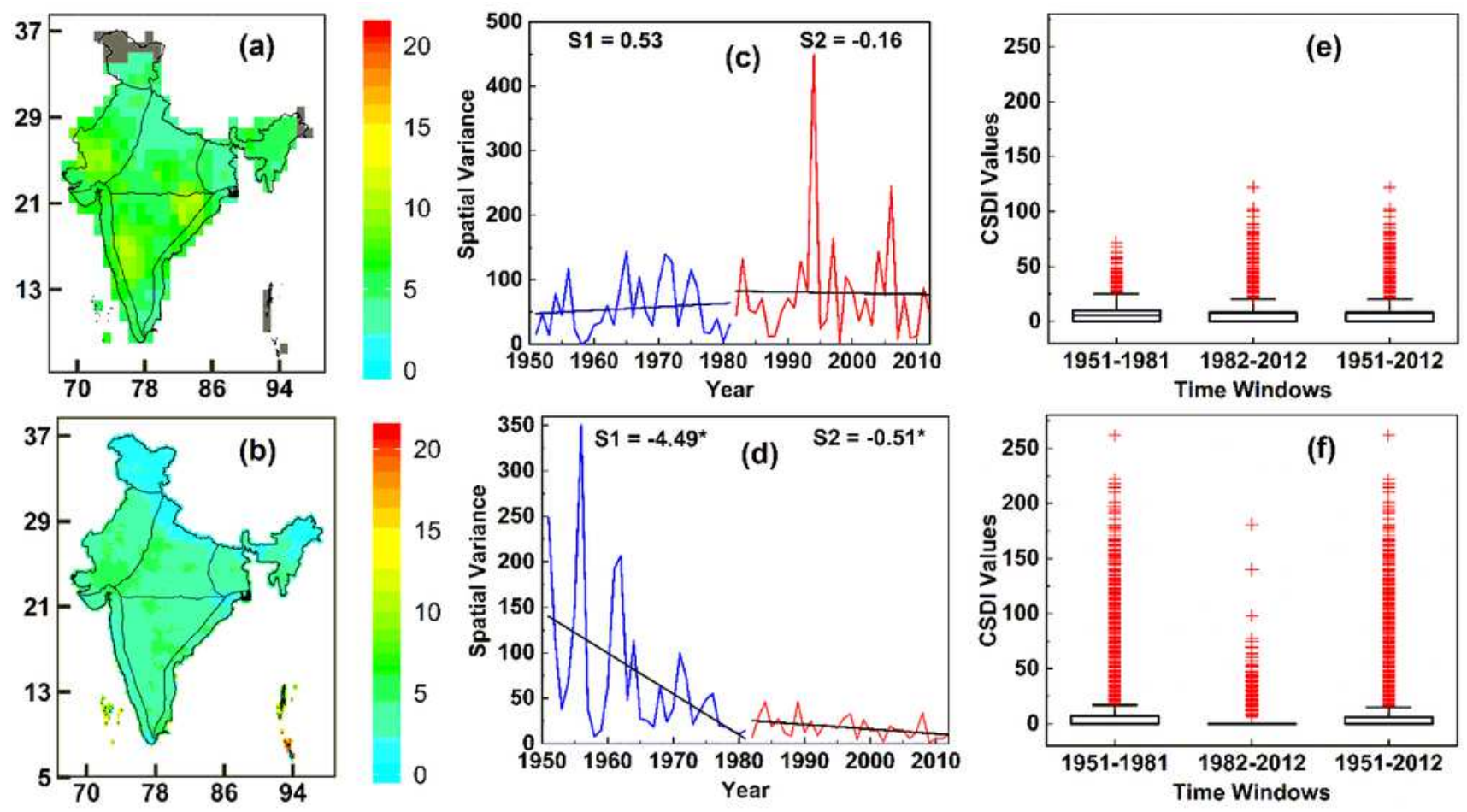

IMD 1951-1981

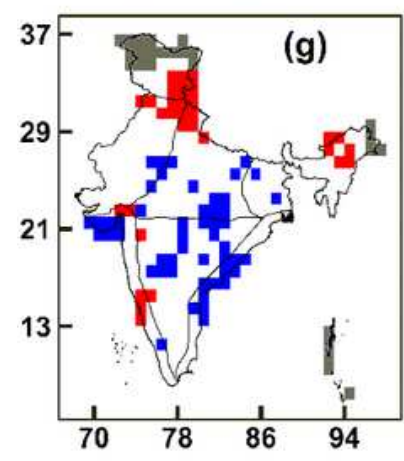

IMD 1982-2012
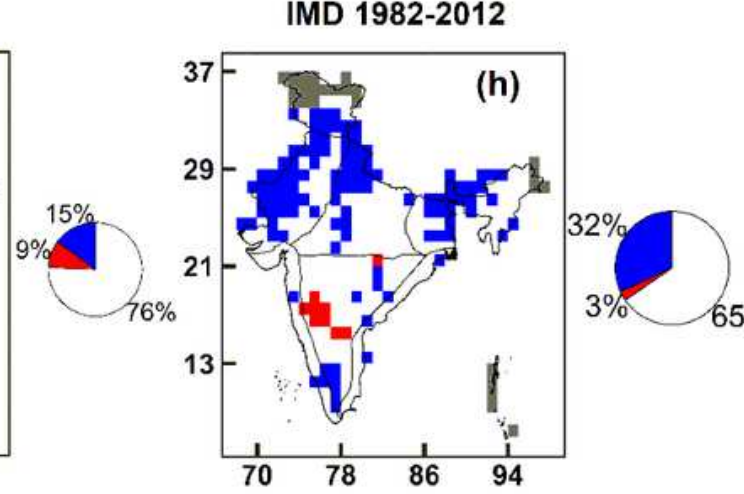

Sheffield 1951-1981

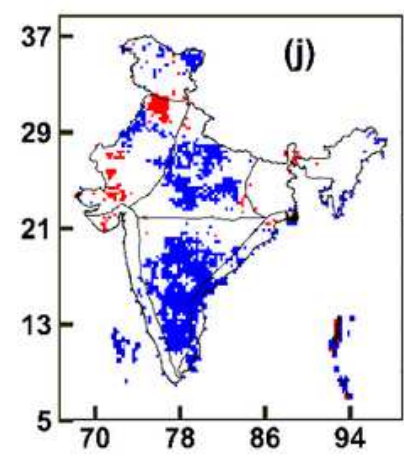

Sheffield 1982-2012

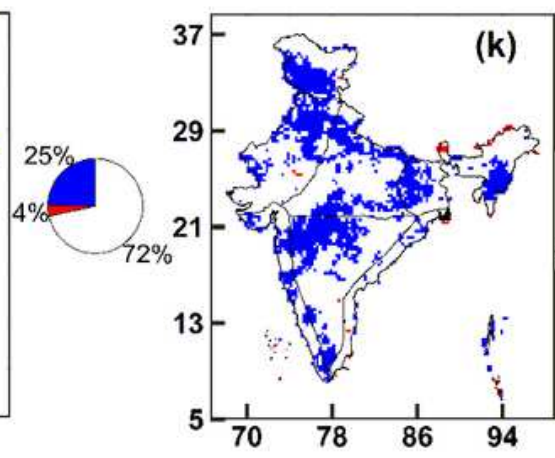

IMD 1951-2012

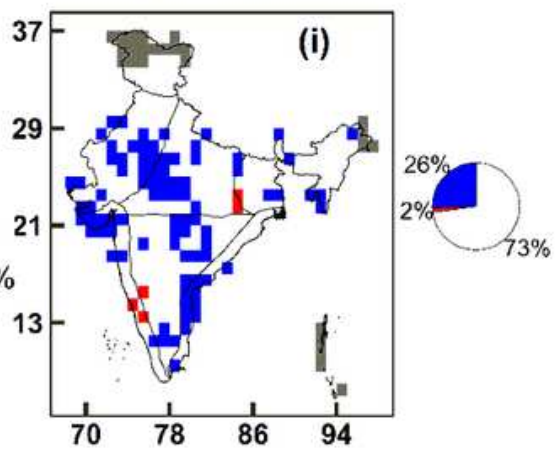

Sheffield 1951-2012

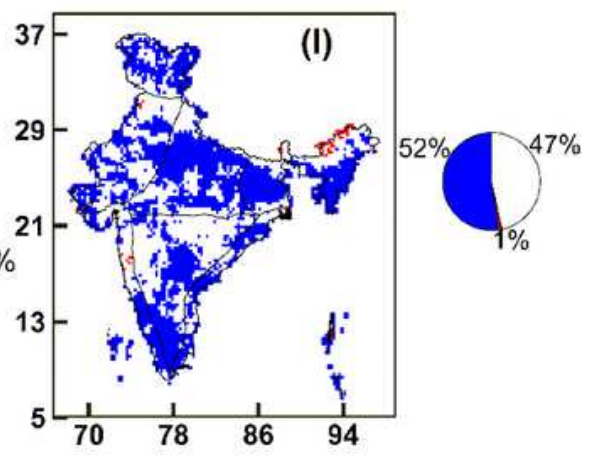




\section{Figure 6}

Mean TX90p for period 1951-2012 (a) IMD (b) Sheffield ; TX90p spatial variance over India, asterisk denotes significant trend (at 5\% significance level) (c) IMD (d) Sheffield ; TX90p Box Plot for three time windows (e) IMD (f) Sheffield ; TX90p trend (at 5\% significance level) in three time windows for IMD (g)1951-1981 (h)1982-2012 (i)1951-2012, for Sheffield (j)1951-1981 (k)1982-2012 (l)1951-2012; Grids with significant increasing trend, significant decreasing trend, no trend and inconsistent data are shown in red, blue, white and grey color respectively; Pie chart on right side shows percentage of grids having significant increasing, significant decreasing and no trend. 


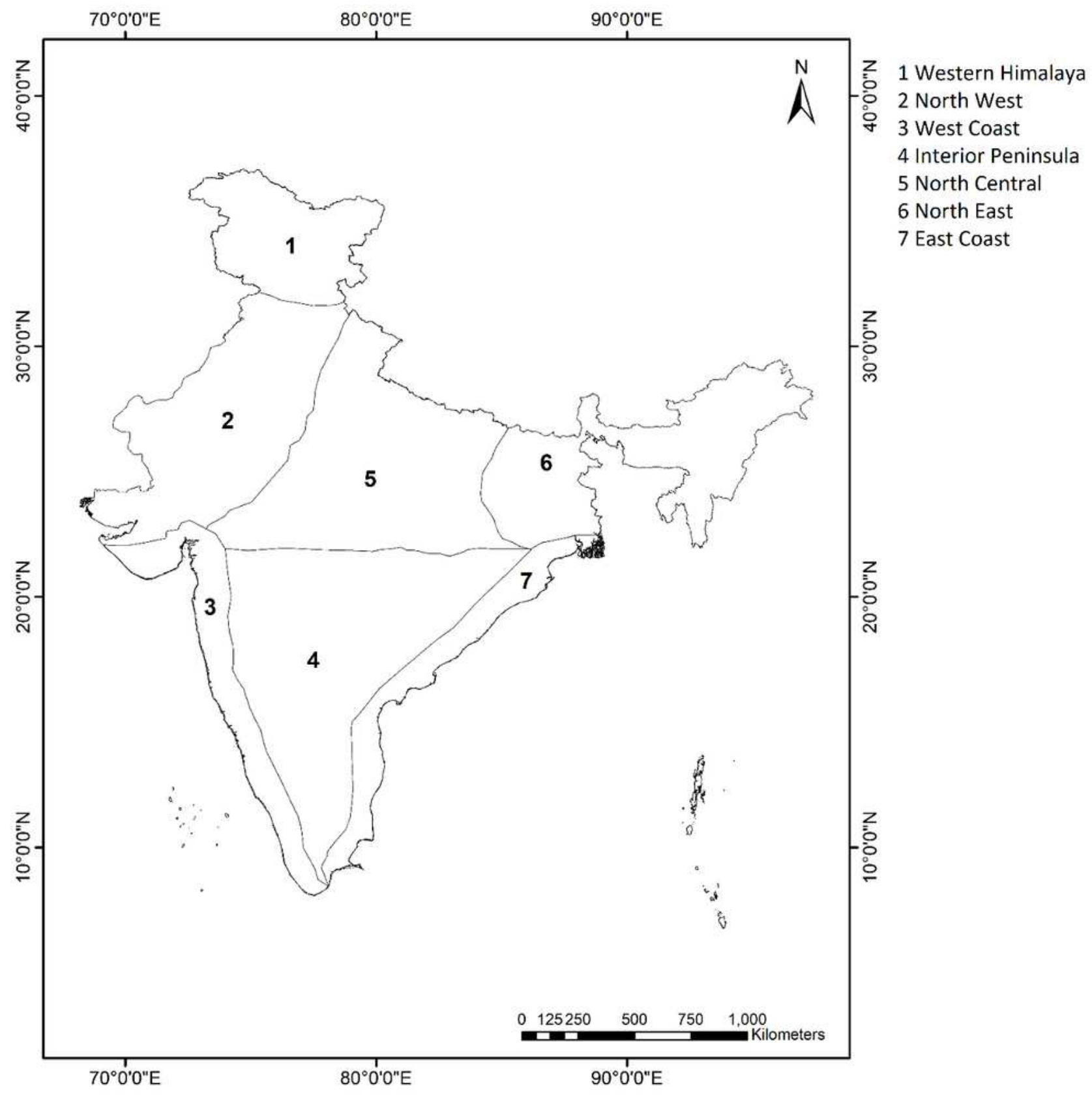

\section{Figure 7}

Mean TN90p for period 1951-2012 (a) IMD (b) Sheffield ; TN90p spatial variance over India, asterisk denotes significant trend (at 5\% significance level) (c) IMD (d) Sheffield ; TN90p Box Plot for three time windows (e) IMD (f) Sheffield ; TN90p trend (at 5\% significance level) in three time windows for IMD (g)1951-1981 (h)1982-2012 (i)1951-2012, for Sheffield (j)1951-1981 (k)1982-2012 (l)1951-2012; Grids with significant increasing trend, significant decreasing trend, no trend and inconsistent data are shown 
in red, blue, white and grey color respectively; Pie chart on right side shows percentage of grids having significant increasing, significant decreasing and no trend
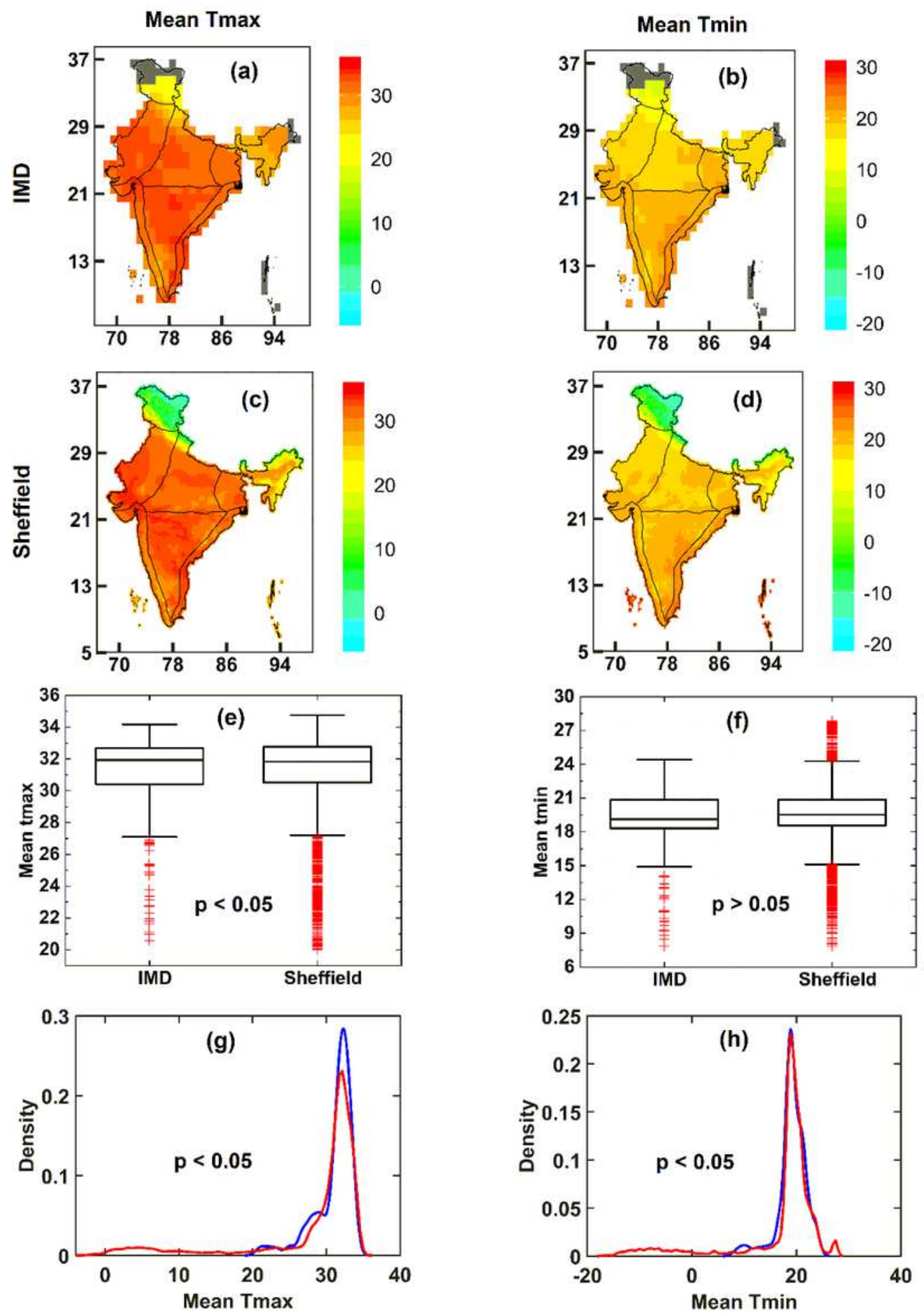

\section{Figure 8}

Mean TR for period 1951-2012 (a) IMD (b) Sheffield ; TR spatial variance over India, asterisk denotes significant trend (at 5\% significance level) (c) IMD (d) Sheffield ; TR Box Plot for three time windows (e) IMD (f) Sheffield ; TR trend (at 5\% significance level) in three time windows for IMD (g)1951-1981 
(h)1982-2012 (i)1951-2012, for Sheffield (j)1951-1981 (k)1982-2012 (I)1951-2012; Grids with significant increasing trend, significant decreasing trend, no trend and inconsistent data are shown in red, blue, white and grey color respectively; Pie chart on right side shows percentage of grids having significant increasing, significant decreasing and no trend.
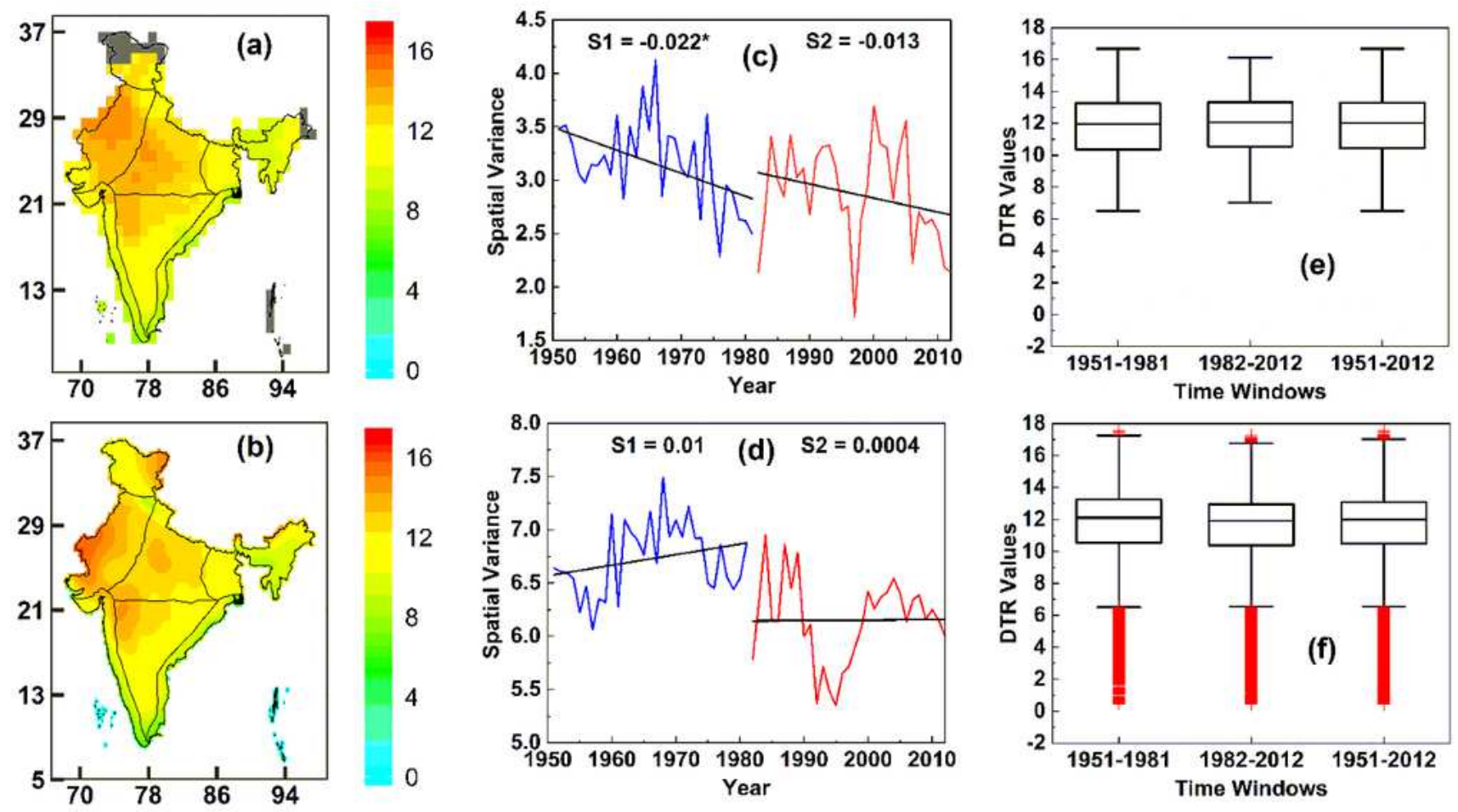

IMD 1951-1981
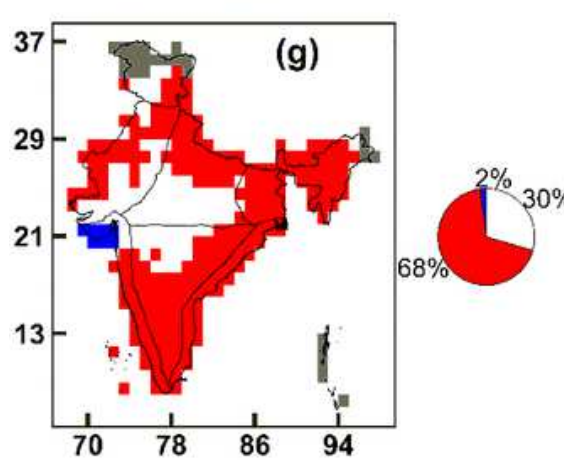

IMD 1982-2012

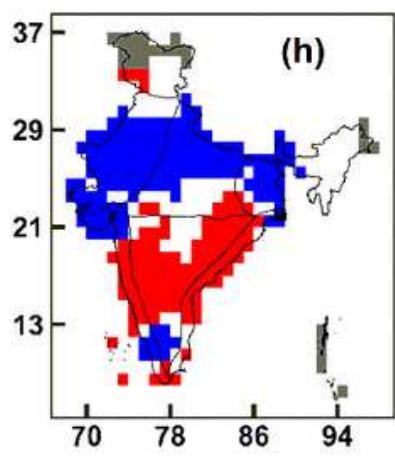

IMD 1951-2012

Sheffield 1951-1981

Sheffield 1982-2012
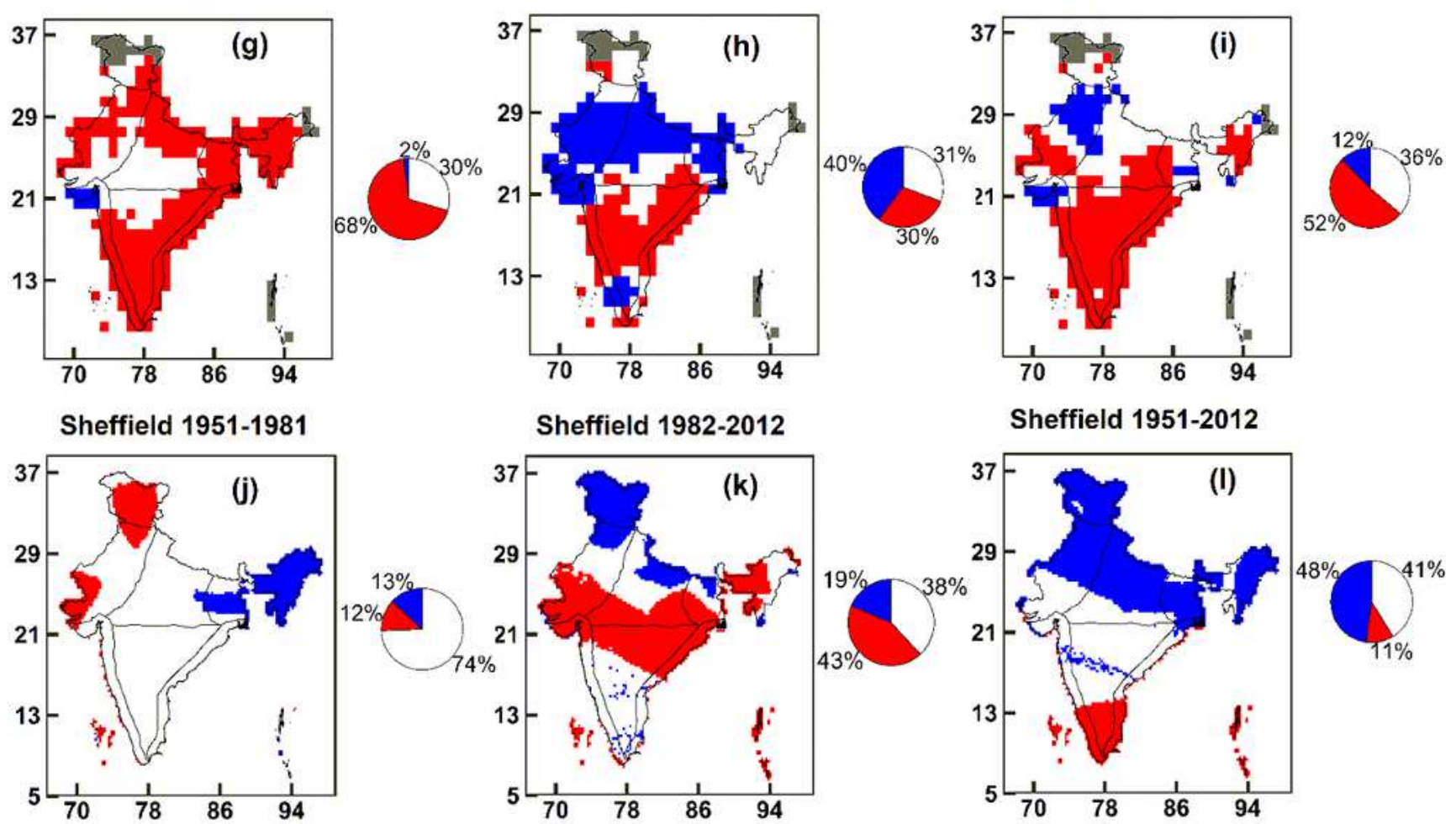

Sheffield 1951-2012
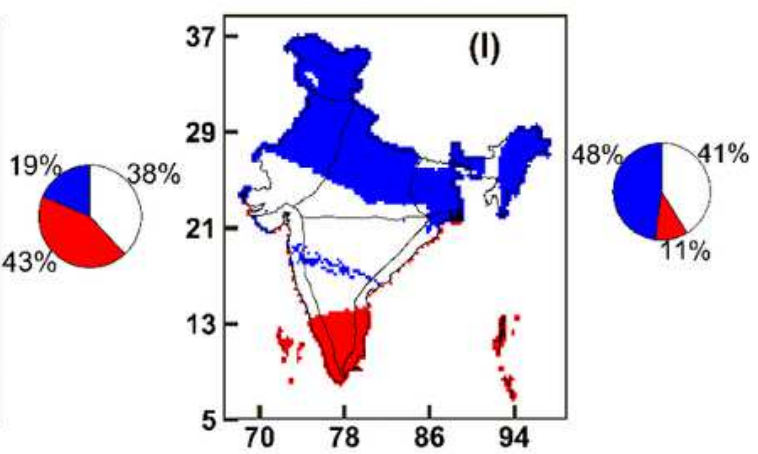

Figure 9 
Mean SU for period 1951-2012 (a) IMD (b) Sheffield ; SU spatial variance over India, asterisk denotes significant trend (at $5 \%$ significance level) (c) IMD (d) Sheffield ; SU Box Plot for three time windows (e) IMD (f) Sheffield ; SU trend (at 5\% significance level) in three time windows for IMD (g)1951-1981 (h)1982-2012 (i)1951-2012, for Sheffield (j)1951-1981 (k)1982-2012 (I)1951-2012; Grids with significant increasing trend, significant decreasing trend, no trend and inconsistent data are shown in red, blue, white and grey color respectively; Pie chart on right side shows percentage of grids having significant increasing, significant decreasing and no trend.
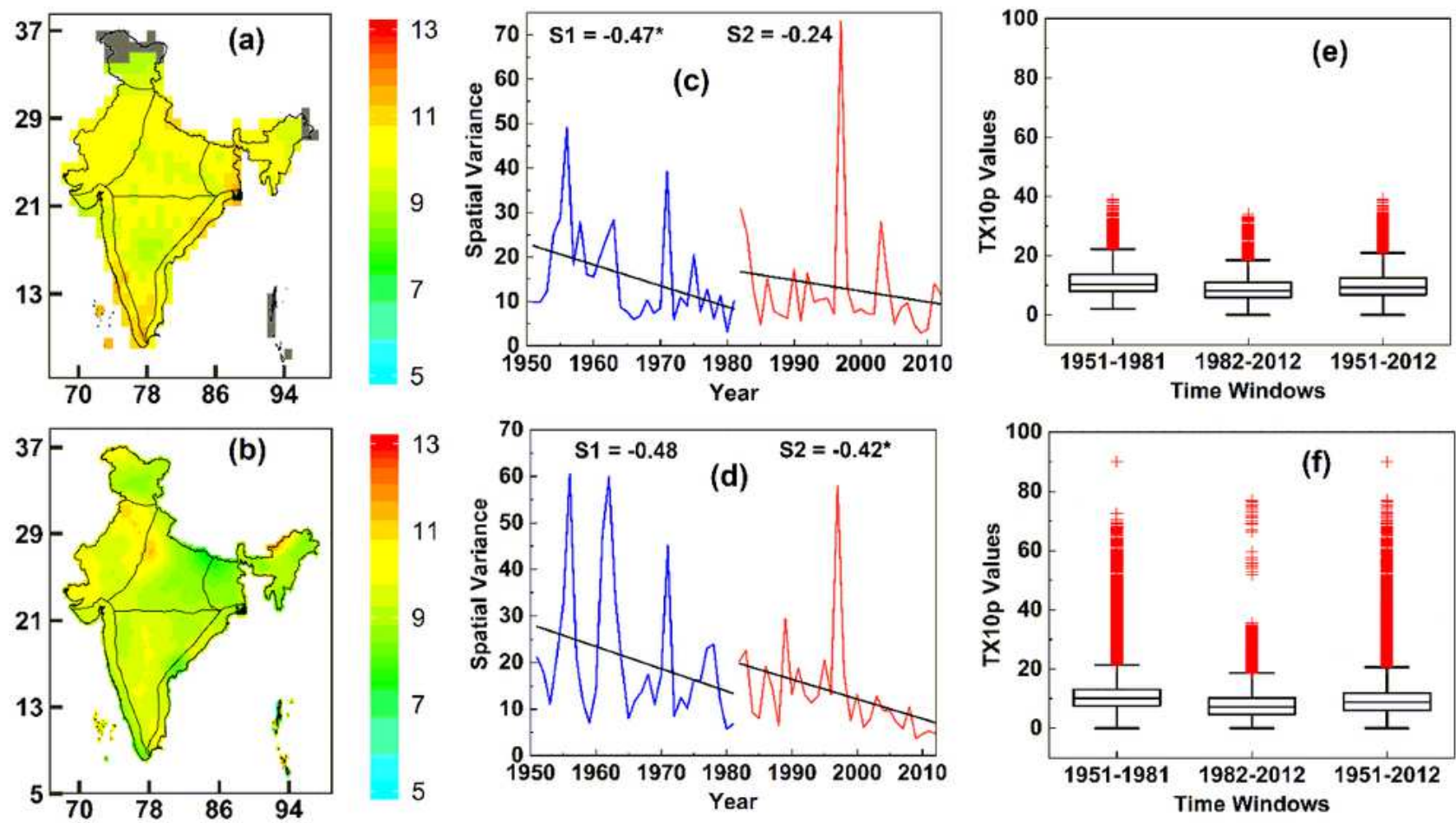

IMD 1951-1981
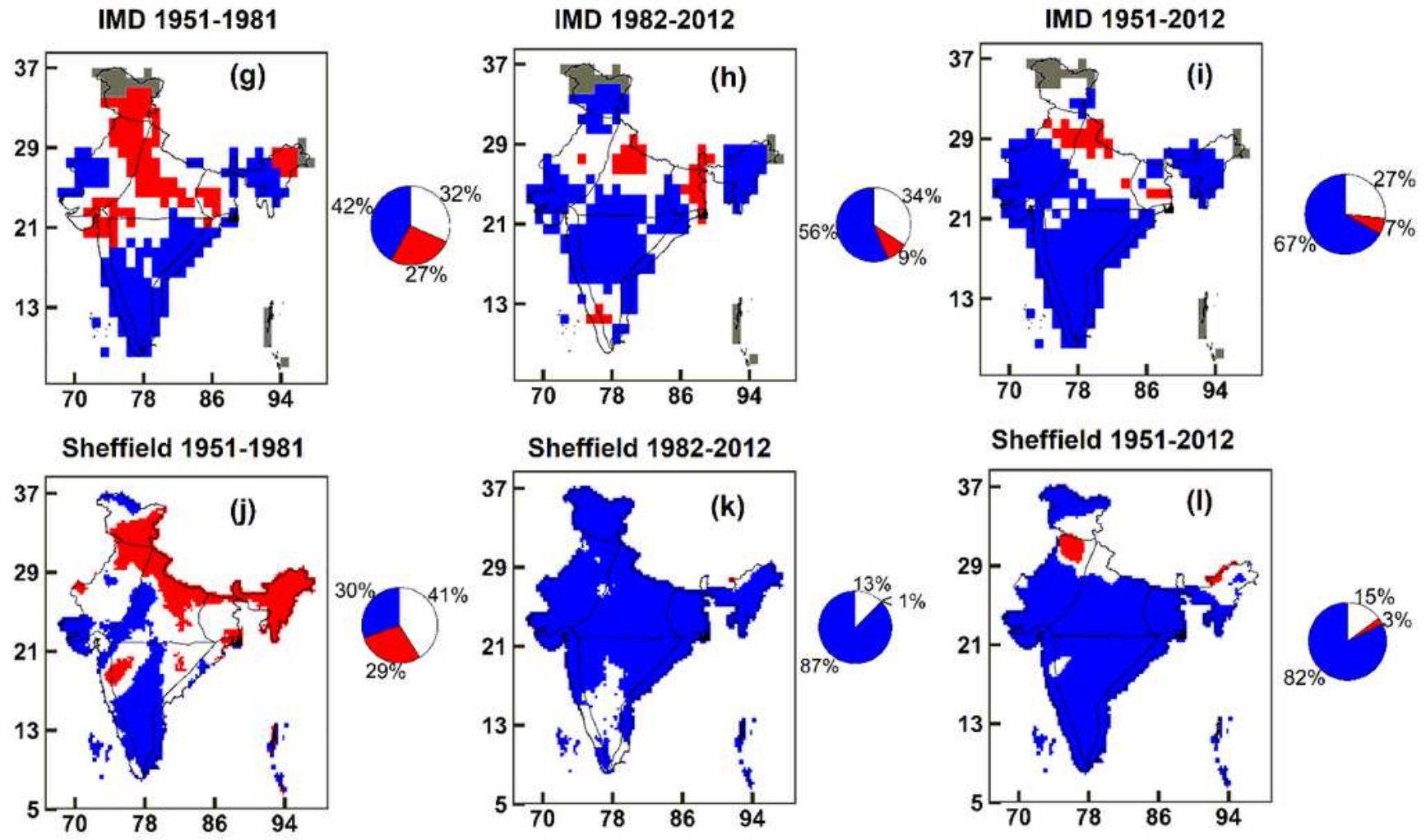

\section{Sheffield 1951-2012}

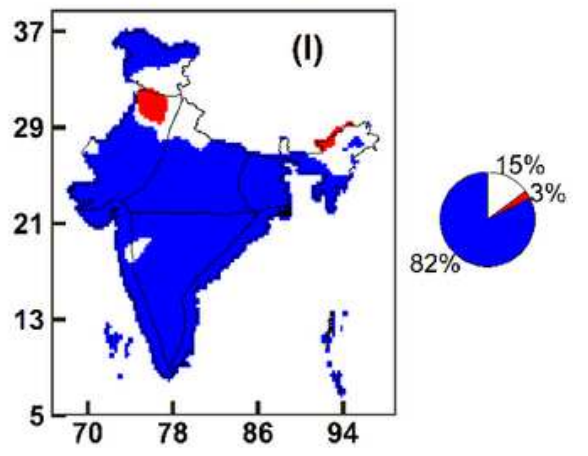




\section{Figure 10}

Mean WSDI for period 1951-2012 (a) IMD (b) Sheffield ; WSDI spatial variance over India, asterisk denotes significant trend (at 5\% significance level) (c) IMD (d) Sheffield ; WSDI Box Plot for three time windows (e) IMD (f) Sheffield ; WSDI trend (at 5\% significance level) in three time windows for IMD (g)1951-1981 (h)1982-2012 (i)1951-2012, for Sheffield (j)1951-1981 (k)1982-2012 (l)1951-2012; Grids with significant increasing trend, significant decreasing trend, no trend and inconsistent data are shown in red, blue, white and grey color respectively; Pie chart on right side shows percentage of grids having significant increasing, significant decreasing and no trend. 

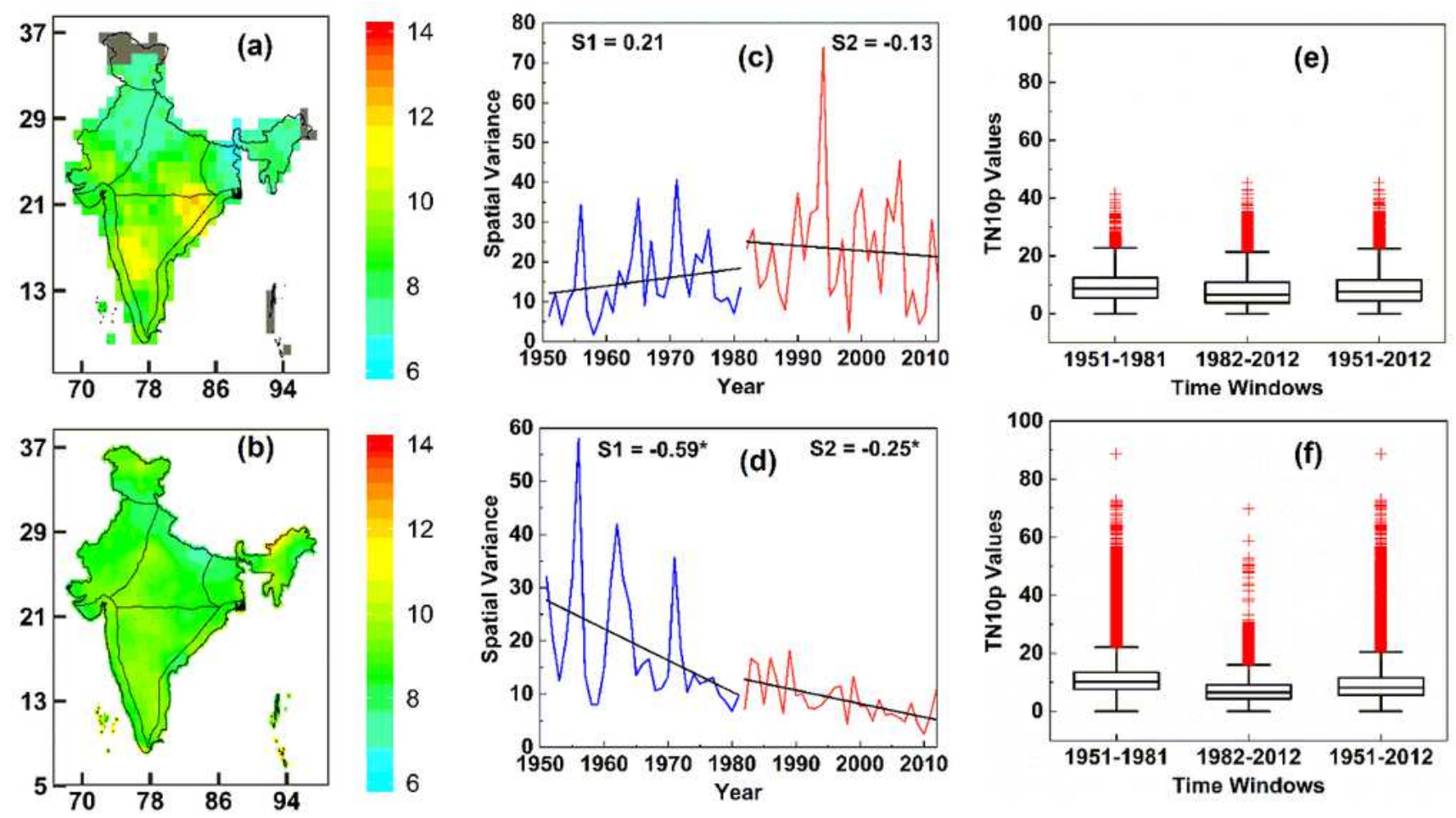

IMD 1951-1981
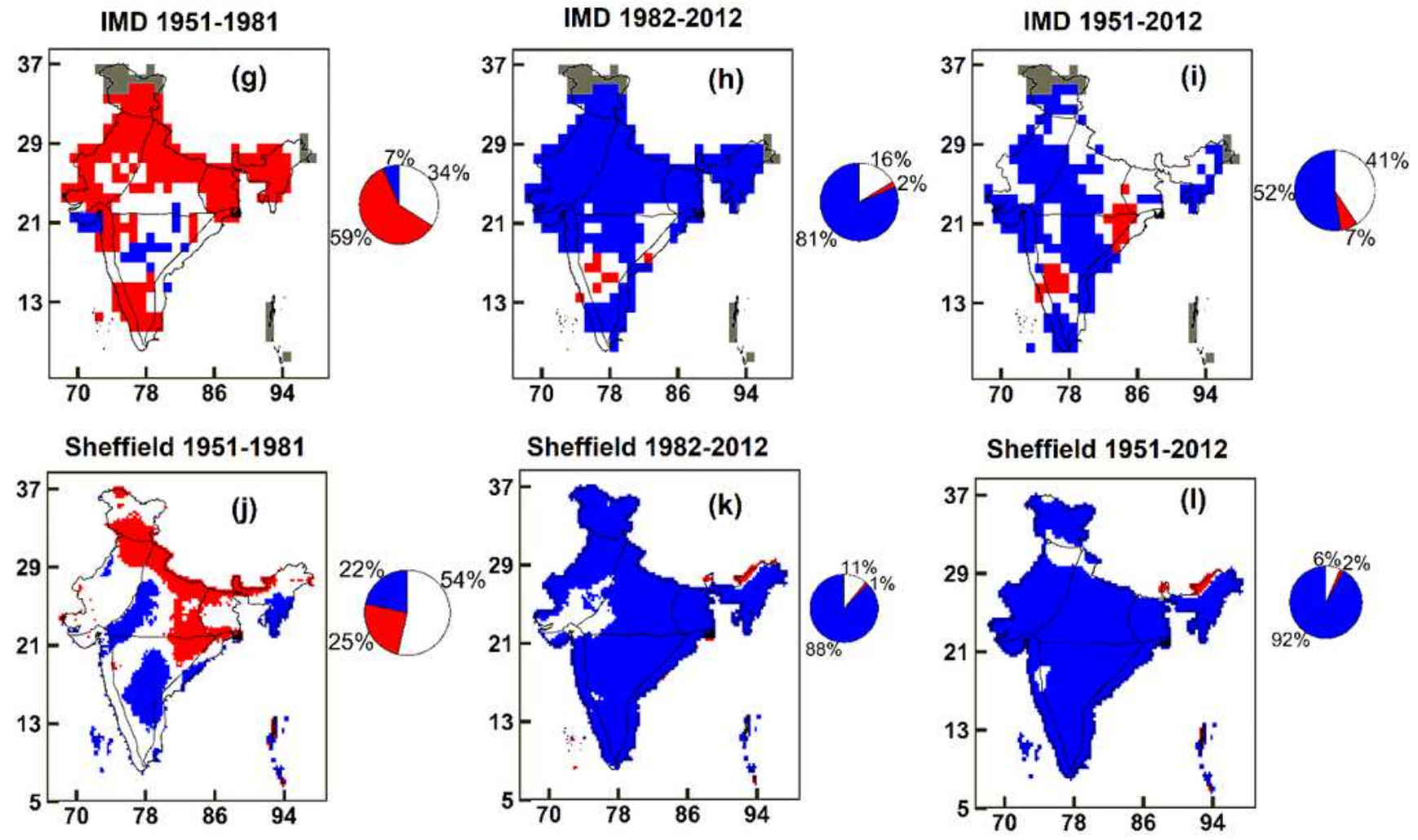

Figure 11

Mean CSDI for period 1951-2012 (a) IMD (b) Sheffield ; CSDI spatial variance over India, asterisk denotes significant trend (at 5\% significance level) (c) IMD (d) Sheffield; CSDI Box Plot for three time windows (e) IMD (f) Sheffield ; CSDI trend (at 5\% significance level) in three time windows for IMD (g)1951-1981 (h)1982-2012 (i)1951-2012, for Sheffield (j)1951-1981 (k)1982-2012 (I)1951-2012; Grids with significant increasing trend, significant decreasing trend, no trend and inconsistent data are shown in red, blue, white 
and grey color respectively; Pie chart on right side shows percentage of grids having significant increasing, significant decreasing and no trend.

\section{Supplementary Files}

This is a list of supplementary files associated with this preprint. Click to download.

- SupportingInformationTAC.docx 